\title{
Cell cycle checkpoint control: The cyclin G1/Mdm2/p53 axis emerges as a strategic target for broad-spectrum cancer gene therapy - A review of molecular mechanisms for oncologists
}

\author{
ERLINDA M. GORDON ${ }^{1-3}$, JOSHUA R. RAVICZ ${ }^{1}$, SEIYA LIU ${ }^{4}$, \\ SANT P. CHAWLA ${ }^{1}$ and FREDERICK L. HALL ${ }^{2,3}$ \\ ${ }^{1}$ Cancer Center of Southern California/Sarcoma Oncology Center, Santa Monica, CA 90403; \\ ${ }^{2}$ Aveni Foundation and ${ }^{3}$ DELTA Next-Gen, LLC, Santa Monica, CA 90405; \\ ${ }^{4}$ Department of Cell Biology, Harvard University, Cambridge, MA 02138, USA
}

Received April 16, 2018; Accepted June 14, 2018

DOI: $10.3892 / \mathrm{mco} .2018 .1657$

\begin{abstract}
Basic research in genetics, biochemistry and cell biology has identified the executive enzymes and protein kinase activities that regulate the cell division cycle of all eukaryotic organisms, thereby elucidating the importance of site-specific protein phosphorylation events that govern cell cycle progression. Research in cancer genomics and virology has provided meaningful links to mammalian checkpoint control elements with the characterization of growth-promoting proto-oncogenes encoding c-Myc, Mdm2, cyclins A, D1 and G1, and opposing tumor suppressor proteins, such as $\mathrm{p} 53$, $\mathrm{pRb}, \mathrm{p} 16^{\mathrm{INK} 4 \mathrm{~A}}$ and $\mathrm{p} 21^{\mathrm{WAF} 1}$, which are commonly dysregulated in cancer. While progress has been made in identifying numerous enzymes and molecular interactions associated with cell cycle checkpoint control, the marked complexity, particularly the functional redundancy, of these cell cycle control enzymes in mammalian systems, presents a major challenge in discerning an optimal locus for therapeutic intervention in the clinical management of cancer. Recent advances in genetic engineering, functional genomics and clinical oncology converged in identifying cyclin G1 (CCNG1 gene) as a pivotal component of a commanding cyclin G1/Mdm2/p53 axis and a strategic locus for re-establishing cell cycle control by means of therapeutic gene transfer. The purpose of the present study is to provide a focused review of cycle checkpoint control as a practicum for clinical oncologists with an interest in applied molecular medicine. The aim is to present a unifying model that: i) clarifies the function of cyclin G1 in establishing proliferative competence, overriding p53 checkpoints and advancing cell cycle
\end{abstract}

Correspondence to: Dr Erlinda M. Gordon, Cancer Center of Southern California/Sarcoma Oncology Center, 2811 Wilshire Boulevard, Suite 414, Santa Monica, CA 90403, USA

E-mail: erlinda.gordon@gmail.com

Key words: CCNG1, cyclin-dependent kinase, protein phosphatase 2A, tumor suppressor, p53, Mdm2, proto-oncogene, gene delivery, microRNAs, cancer gene therapy, Rexin-G progression; ii) is supported by studies of inhibitory microRNAs linking $C C N G 1$ expression to the mechanisms of carcinogenesis and viral subversion; and iii) provides a mechanistic basis for understanding the broad-spectrum anticancer activity and single-agent efficacy observed with dominant-negative cyclin G1, whose cytocidal mechanism of action triggers programmed cell death. Clinically, the utility of companion diagnostics for cyclin G1 pathways is anticipated in the staging, prognosis and treatment of cancers, including the potential for rational combinatorial therapies.

\section{Contents}

1. Introduction

2. Tumor initiation, tumor promotion, and Ser/Thr protein phosphorylation: Then and now

3. Focus on cyclin-dependent targeting of proline-directed protein phosphorylation

4. Focus on G1-phase regulation: Oncogenic cyclins vis-à-vis tumor suppressive gatekeepers

5. Targeting CDKs and CDK inhibitors (CDKIs) for cancer therapy: Current status, issues

6. Cyclin G1, a non-canonical cyclin, opposes p53, the fragile 'guardian of the genome'

7. The commanding cyclin $\mathrm{G} 1 / \mathrm{Mdm} 2 / \mathrm{p} 53$ axis operating in normal and neoplastic cells

8. Targeting cyclin G1 function in experimental hyperplasia: Applications to cancer control

9. Development of a targeted retroviral vector to efficiently deliver the dnG1 designer gene

10. Clinical studies demonstrate broad-spectrum anticancer activity and single-agent efficacy

11. Restoring long-lost tumor suppression with a dominant-negative cyclin $\mathrm{G} 1$ antagonist

12. Cyclin G1 proto-oncogene promotes cell survival and progression over DNA fidelity

13. Combinatorial approaches and companion diagnostics for cyclin G1-targeted therapies

14. Conclusions 


\section{Introduction}

Decades of research in the fields of biochemistry, cell biology, molecular genetics, virology, genetic engineering, functional genomics and cancer gene therapy, have converged in identifying the executive components of a commanding regulatory axis of mammalian cell cycle control: Providing new mechanistic insights, biochemical pathways, unifying concepts and checkpoint control elements with profound implications in the prevention, diagnosis and treatment of cancer (Fig. 1). The challenge remains, however, to successfully integrate these celebrated epochs of gene discovery and biochemical pathway characterization into a practical understanding of cell cycle control befitting the actual praxis and applied pharmacology of contemporary clinical oncologists. This focused review, prepared by contributing scientists and clinical practitioners in the field of genetic medicine, is intended to present the current state-of-the-art in applied cell cycle checkpoint control as it relates to cancer management.

\section{Tumor initiation, tumor promotion and Ser/Thr protein phosphorylation: Then and now}

From a clinical perspective, the molecular mechanisms of chemical co-carcinogenesis first came to light in the 1940s with the pioneering studies of croton oil (i.e., phorbol esters) and 3,4-benzpyrene in a now-classic mouse skin model (1), in which increased tumor production was only observed when the inflammatory phorbol ester followed, rather than preceded, the application of the DNA-damaging carcinogen, thereby defining the separable and discernible stages of tumor initiation, promotion and progression (2). The subsequent discovery that protein kinase $\mathrm{C}$ (PKC), which plays a major role in signal transduction and cell proliferation, is the cellular receptor for the tumor-promoting phorbol esters (3) ushered in a wave of pharmaceutical interest in selective PKC inhibitors, only to be thwarted by the general multifunctionality of PKC, the multiplicity of PKC isoenzymes, the limited specificity of PKC modulators and the remaining unanswered questions and intricacies of PKC function, which stifled the promise of targeting PKCs for cancer therapeutics (4). Nevertheless, the importance of discrete Ser/Thr kinase activities, which operate via recognition-site-specific protein phosphorylation events, in the control of biochemical pathways governing mammalian cell growth and proliferation, as well as tumorigenesis, invasion and metastasis, has emerged as a major regulatory theme.

\section{Focus on cyclin-dependent targeting of proline-directed protein phosphorylation}

Basic research in yeast genetics characterized a number of cell division cycle (Cdc) mutants, thereby identifying important genes, notably $\mathrm{Cdc} 28$ in baker's yeast (S. cerevisiae) and its homologue $\mathrm{Cdc} 2$ in fission yeast (S. pombe), which encode a unique serine/threonine protein kinase that is not only critical for mitosis in yeast, but is highly conserved in both structure and function throughout the evolution of all eukaryotes, including Homo sapiens (5). The molecular cloning and characterization of the $\mathrm{Cdc} 2 / \mathrm{Cdc} 28$ kinase (CDK1 in mammals) and its implicit role in governing the defined stages and checkpoints of the eukaryotic cell division cycle supported by the independent discovery of cyclins A and B as prominent oscillating proteins of unknown function in sea urchin embryos (A. punctata), which were eventually cloned, biochemically characterized and determined to be positive-acting regulatory subunits of the executive $\mathrm{Cdc} 2 / \mathrm{Cdc} 28$ kinase, thereby linking nascent protein synthesis (i.e., cyclin proteins) to the ordered stepwise progression of the cell division cycle through its defined phases (6). From this point onwards, the term 'cyclin-dependent' kinase (CDK) has been used to characterize the vertebrate homologs of this key regulatory enzyme. Recognized as a triumph of basic research in simple model systems, as well as a major advance in terms of elaborating the executive enzymology regulating cell cycle transitions, the principal investigators, Hartwell, Nurse and Hunt, were awarded the Nobel Prize for Medicine in 2001 (7). Armed with the DNA coding sequences for both the catalytic subunit (kinase) and the putative regulatory subunits (cyclins) of this executive protein kinase from primitive eukaryotic model systems, the molecular cloning and characterization of homologous coding sequences in higher animals began in earnest $(8,9)$, enabling scientists to solve a lingering paradox in modern cell biology, i.e., the molecular basis for deconstructing cell cycle regulation in higher animals into two separable and distinct protein kinase activities, each with very different substrate specificities: The purified mitosis-promoting factor (MPF), which controls the G2-to-M phase transition (10) vis-à-vis the $\mathrm{S}$ phase-promoting factor (SPF), which orchestrates the G1-to-S phase transition $(11,12)$.

Mechanistic insights were derived from international studies of site-specific protein phosphorylation in rat pheochromocytoma, which led to the identification and characterization of the growth factor-sensitive proline-directed protein kinase (PDPK), based on its ability to phosphorylate a unique site on tyrosine hydroxylase, a key regulatory enzyme in the synthesis of adrenal catecholamines (13). These collaborative studies led to the discovery that the preferred amino acid sequence recognized by this unique interphase kinase activity, in terms of substrate specificity, is $\mathrm{X}$-Ser/Thr-Pro-X-X, thereby predicating the requirement for a single orienting proline residue immediately adjacent to the actual phosphorylation site (14), affirming the appellation 'proline-directed' protein kinase, and presenting this unique Ser/Thr kinase activity (which is biochemically distinguishable from the M phase-specific histone H1 kinase activity of purified MPF) as a likely candidate for the illusive SPF in mammals (15). Structurally, the high frequency of S-P-X-X and T-P-X-X motifs (presumably type-1 $\beta$-turns) found in gene regulatory proteins is not only indicative of a new DNA-binding unit (16), but also of proline-directed protein phosphorylation sites that have been canalized by natural selection, along with this site-specific protein kinase activity.

Molecular cloning and characterization of homologous kinase subunits in vertebrates revealed that the biochemical and physiological activities of MPF are attributable to CDK1/cyclin B complexes, the Ser/Thr kinase activity of which regulates the cytoskeletal dynamics associated with mitosis $(10,12)$. In 1991, Hall et al characterized the subunits of the purified PDPK as a complex of CDK1 and cyclin A (17); when $\mathrm{CDK} 2$, a second homologue of the yeast $\mathrm{Cdc} 2 / \mathrm{Cdc} 28$ kinase, was identified in humans, this homologous kinase, which is expressed somewhat earlier in the cell cycle compared 
Timeline: Cell cycle checkpoint control from the bench to the bedside

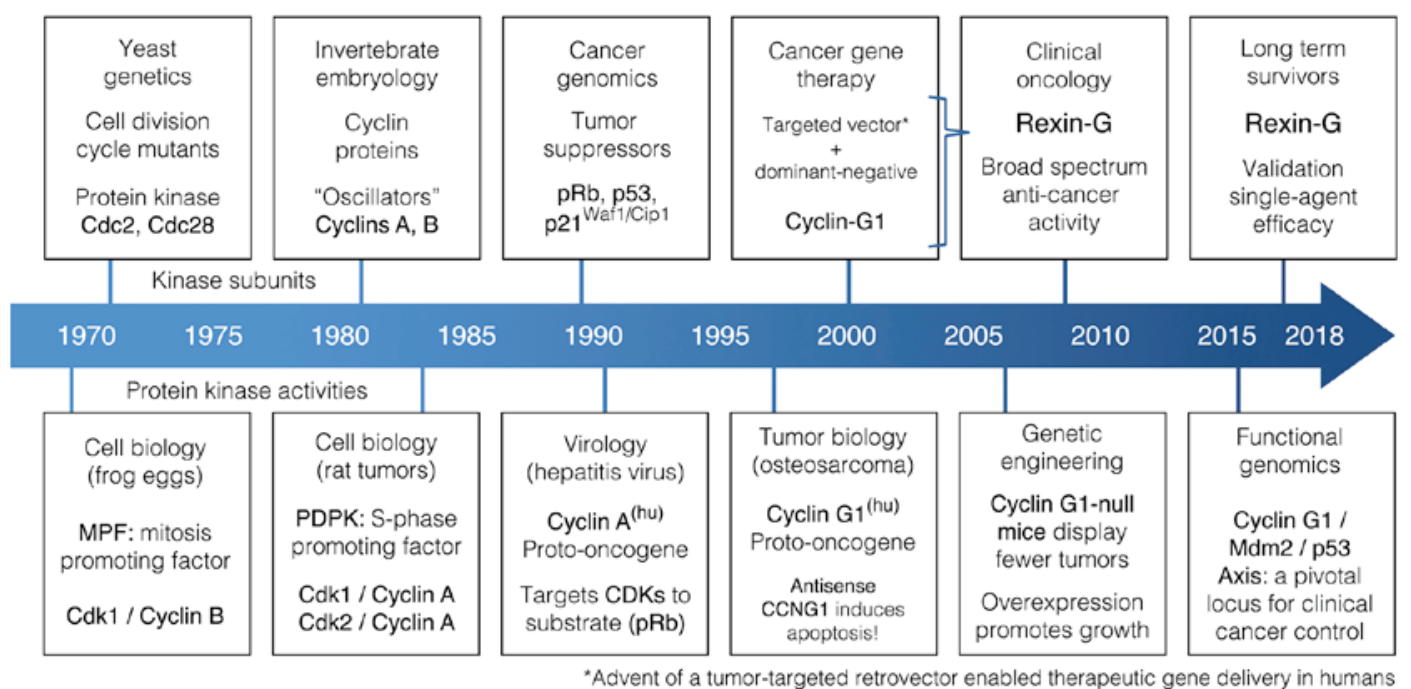

Figure 1. Timeline of multidisciplinary milestones in the development of cancer gene therapy.

with CDK1, was also found to partner with cyclin A and is enzymatically active as a CDK2/cyclin A heterodimer (18). Moreover, in addressing the paradox of differential substrate specificities, it was determined that the cyclin A subunit of these CDK complexes not only acts as a positive regulatory subunit, in terms of kinase activation, but it is the inducible 'cyclin' subunit that determines the substrate specificity of the active protein kinase. In this case, the cyclin A subunit physically targets the cyclin A/CDK holoenzymes to the Retinoblastoma ( $\mathrm{Rb}$ ) tumor suppressor protein (19), where progressive site-specific phosphorylation of $\mathrm{pRb}$ serves to inactivate the tumor suppressor (i.e., transcription/E2F repressor) (20), thereby linking the molecular activation of G1-phase transcription in humans to the expression of specific cyclin proteins (21). The cyclin-targeted CDK activities serve to overcome the suppressive function of Rb-related 'pocket' proteins (pRb, p107 and p130) that govern the feed-forward mechanics of the cell cycle, i.e., the coupling of protein phosphorylation and gene transcription, which drives cell cycle progression $(22,23)$.

\section{Focus on G1-phase regulation: Oncogenic cyclins vis-à-vis tumor suppressive gatekeepers}

A fundamental characteristic of cancer genetics is the molecular dysregulation of cell cycle checkpoint control elements, which normally ensures the orderly progression of cell growth, DNA synthesis and mitotic cell division, while actively ensuring genomic fidelity. Among the manifold genetic alterations known to contribute to the pathogenesis of cancer in humans, including the molecular genetic disruptions of tumor viruses, the majority of these mutations are observed in genes that regulate progression through the G1 phase of the cell division cycle, including pRb-related tumor-suppressor proteins, which govern cell cycle progression, and the much-studied p53 tumor suppressor (mutated in $>50 \%$ of human cancers), which serves as a molecular 'guardian' of DNA fidelity and an 'executioner' via its pro-apoptotic function (24). Alterations in the enzymatic machinery that controls the decisions to progress from a resting state (G0) into the cell cycle (G0-to-G1 transition) and/or to progress from the $\mathrm{G} 1$ to the $\mathrm{S}$ phase led to the identification of a growing family of human cyclins and their CDK partners that are directly implicated in the mechanisms of tumorigenesis and cancer (25-27). Thus, it is becoming abundantly clear that the major tumor suppressive elements (i.e., pRb and p53) that control progression through the mammalian cell cycle (28) are themselves a target for molecular inactivation by the expression and growth-promoting activities of two distinct types of potentially oncogenic cyclin proteins: The G1 cyclins (D-, E- and A-type cyclins) targeting CDKs to the Rb-Axis, and the perplexing cyclin G1, which disables the functions of p53 (Fig. 2).

The regulatory importance of human G1 cyclin expression in the promotion of cell proliferation and cancer is indicated by the telltale manner of their discovery and cloning in humans, which is directly linked to the pathogenesis of neoplastic disease. Human cyclin A was first identified biochemically as a co-precipitate, along with the $\mathrm{pRb}$ tumor suppressor, in a screen for proteins that bind with high affinity to the cell-transforming adenoviral E1A oncoprotein (29); soon thereafter, the molecular cloning of the human cyclin A gene was achieved by tracking the various insertion sites where the hepatitis B virus (HBV) physically integrates into the human genome (30). Importantly, it was determined that the HBV-induced dysregulation of the human cyclin A locus not only enforces a generalized overexpression of the gene, but it also physically mutated/truncated the N-terminal segment of the cyclin A protein, removing signal sequences necessary for its cyclical proteolytic degradation and producing a hybrid HBV-cyclin A transcript encoding a 'stabilized' cyclin A protein (hence interphase PDPK activity), which may indeed participate in the development and progression of hepatocellular carcinoma (HCC) (31). In subverting the cyclin A locus, a key component of the mammalian cell cycle machinery, the transforming HBV had apparently created a 'dominant-positive' mutant gene product to essentially commandeer cell cycle 


\section{CYCLINS: Abrogate key tumor suppressors governing cell cycle progression}

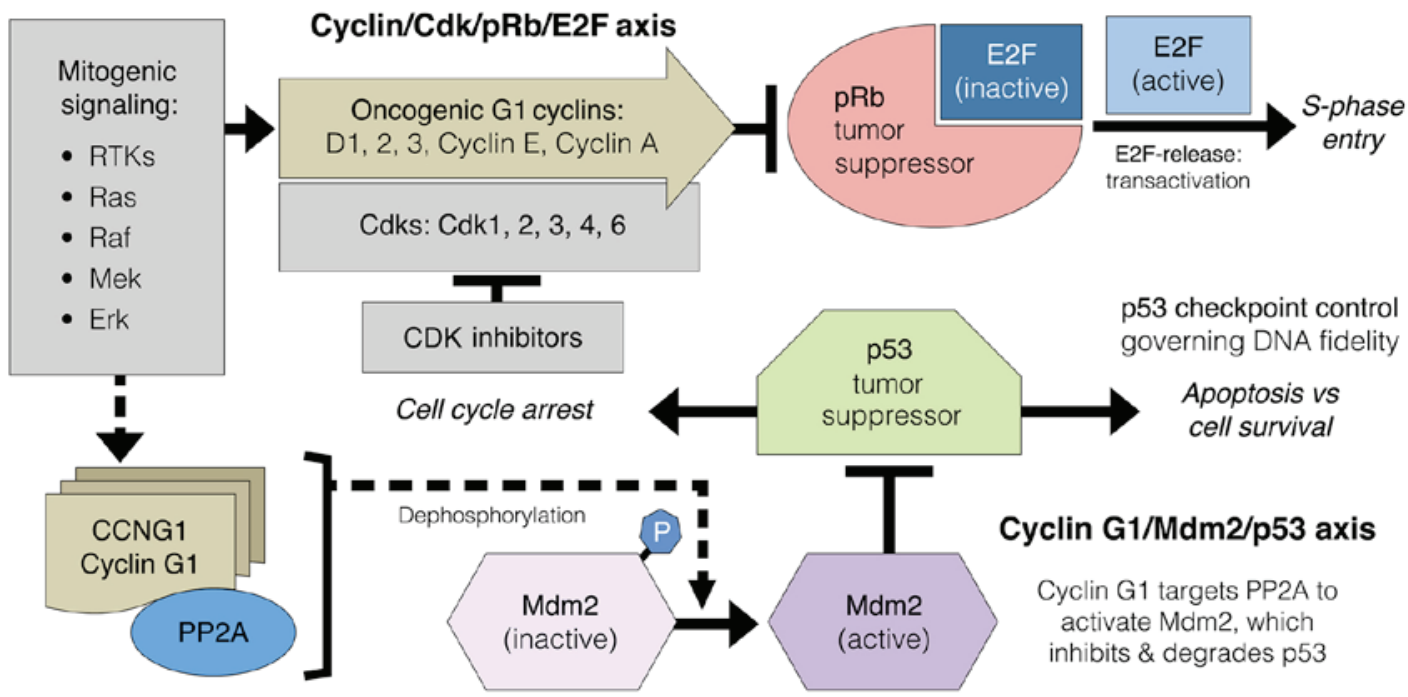

Figure 2. Diagram of oncogenic G1 cyclin functions arrayed in biochemical opposition to the pRb tumor suppressor protein that governs cell cycle progression (cyclin/CDK/Rb/E2F axis); this is distinguishable from the function of cyclin G1, which activates the Mdm2 oncoprotein in its opposition to the p53 tumor suppressor that governs cell fate (cyclin G1/Mdm2/p53 axis). CDK, cyclin-dependent kinase; Rb, retinoblastoma.

control by maintaining a critical growth-promoting function of the cyclin A subunit (i.e., kinase activation via the retained 'cyclin box'), while deleting the natural proteolytic processing, which normally eliminates cyclin A entirely, upon completion of each cell division cycle. Such viral subversion and oncogenic activation of a growth-regulatory element identifies human cyclin A as a bona fide proto-oncogene (15,32), and hence a useful biomarker for characterizing tumor cell proliferation in histochemical detail (33).

The identification of the D-type cyclins (D1, D2 and D3) as oncogenes forged new and important links between mitogenic signal transduction, D-type cyclin gene expression and tumorigenesis (34): The growth factor-sensitive cyclin D1 was initially identified as a PRAD1/bcl-1 proto-oncogene, which is subject to gene amplification and/or rearrangement, resulting in cyclin D1 overexpression in a wide spectrum of human cancers, including B-cell neoplasms, carcinomas of the head and neck, various sarcomas and human breast cancers $(>50 \%)$; cyclin D2 was identified as the integration site of a murine leukemia virus, while the cyclin D2 and D3 genes are amplified and overexpressed in numerous human cancers, including leukemias, lymphomas, glioblastomas, colorectal, renal and pancreatic carcinomas $(26,35)$. Partnering promiscuously as heterodimers with a number of CDK subunits (CKD1, 2, 3, 4 and 6), D-type cyclins function in early G1 to target the CDK complexes to the $\mathrm{pRb}$-related tumor suppressor proteins, where site-specific inhibitory phosphorylation of $\mathrm{pRb}$, to a limited extent, primes pRb (36) and advances cell cycle progression to a critical control point in the late G1 phase, known as the restriction point, or R-point (37): This is where the induction of cyclin E-dependent kinase activity contributes to the hyperphosphorylation and inactivation of $\mathrm{Rb}$, thereby releasing the E2F transcription factors and driving cells irreversibly through the G1-to-S phase transition, beyond which additional extracellular signals in the form of mitogenic growth factors are no longer required $(38,39)$. Taken together as an important class of growth-promoting proto-oncogenes, the orderly and progressive expression of specific G1 cyclins (D-type cyclins first, followed by cyclin E and cyclin A) are now viewed as inducible rate-limiting activators of $\mathrm{G} 1$ phase progression, the dysregulation of which is potentially oncogenic.

Just as the executive CDKs of G1 progression are engaged by positive regulatory subunits with profound oncogenic potential (i.e., G1 cyclins), G1 progression is also negatively controlled by polypeptide CDK inhibitors (CDKIs) whose expression is linked with the classical tumor suppressor p53. The finding that $\mathrm{p} 53$, a sequence-specific DNA-binding transcription factor, selectively induces $\mathrm{p} 21^{\mathrm{WAF} 1 / \mathrm{CIP} 1}$ (a universal CDKI) as a mediator of p53-initiated cell cycle arrest, has attracted interest in CDKIs as a strategic locus for prospective therapeutic interventions (40). Indeed, two families of endogenous CDKIs were found to function operationally as tumor suppressors: i) The WAF1/CIP/KIP family of CDKIs (p21, p27 and p57) appear to inhibit the activity of all major CDKs, while the INK4 family of CDKIs (p16, p15, p18 and p19) more specifically inhibit the cyclin D-dependent kinases CDK4 and CDK6, which phosphorylate/inactivate the $\mathrm{pRb}$ suppressor in early G1 $(35,41)$. Of note, genetic alterations involving the p16 ${ }^{\text {INK4a }}$ locus (chromosome 9p21) have been identified as germline mutations in melanoma-prone patients, and as deletions or mutations in a large percentage of primary human tumors, including sarcomas, lymphomas, leukemias, squamous cell carcinomas and pancreatic adenocarcinomas. In addition, genetic engineering of homologous deletions in mice confirmed the overall importance of this locus in the suppression of tumorigenesis $(41,42)$.

\section{Targeting CDKs and CDK inhibitors (CDKIs) for cancer therapy: Current status, issues}

Elucidation of the 'executor' roles of G1 cyclins, CDKs and CDKIs, as they are critical regulatory components of the cell 
MOA I. Tumor suppression

p53-mediated cell cycle arrest



\section{MOA II. Tumor promotion \\ Cyclin G1/PP2A inactivates p53 via Mdm2}
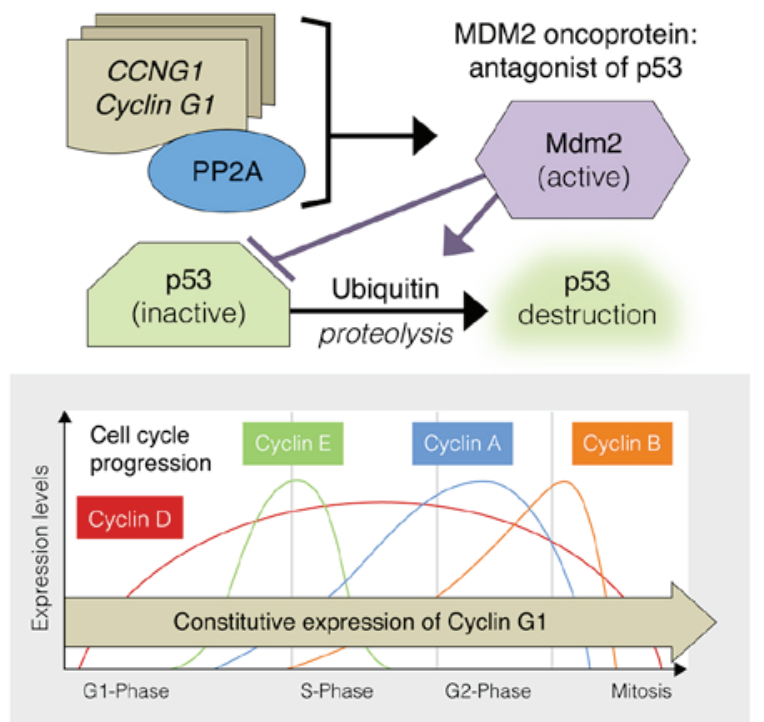

Figure 3. Highlighting dominant features of the commanding cyclin G1/Mdm2/p53 axis in the mechanisms-of-action (MOA) of tumor suppression (MOA I.; left panel) and tumor promotion (MOA II.; right panel). Note: In contrast to the periodic expression of the classic cyclins (D, E, A and B), cyclin G1 expression is normally induced upon 'exit' from quiescence (G0-to-G1 boundary; left panel); however, constitutive expression of cyclin G1 remains constant throughout the cell cycle (bottom right panel).

cycle machinery that are frequently altered in human cancers, prompted renewed interest in the development of specific kinase inhibitors expected to block cell cycle progression and/or induce growth arrest, thereby providing a prospective abundance of targets for novel antineoplastics (43). Unfortunately, but not unexpectedly (see PKC issues above), the first generations of pharmaceutical pan-CDKIs failed to meet such expectations, due to the general lack of target specificity (44). Even the p21WAF1/Cip1 protein, which is the classic pan-CDKI that mediates p53-dependent cell cycle arrest, allowing for DNA repair, is sufficiently complex, in terms of the regulation of its expression, binding activities and subcellular localization, to function operationally, either as a tumor suppressor under certain circumstances (cell cycle block) or as a tumor-promoting oncogene (by preventing apoptosis), depending on the cellular context (45).

Over the past 20 years, a substantial number of prospective pan-CDKIs have been developed as potential cancer therapeutics and tested in numerous clinical trials in a variety of different tumor types, only to fail upon final analysis to meet objective clinical endpoints with an acceptable profile of systemic toxicities $(46,47)$. The principal reasons provided to explain the general failure of non-selective pan-CDKIs in the clinical setting are as follows: i) Lack of clear understanding of the physiological mechanisms of action as to which CDKs are actually being inhibited in vivo; ii) lack of patient selection and stratification on the basis of pertinent companion biomarkers that may help identify a subset of good clinical responders; and iii) lack of a therapeutic window, meaning the inability to achieve therapeutic levels of the drugs due to their intrinsic inability to discriminate between cancerous and healthy tissues (47). Despite the disappointing early attempts to develop pharmaceutical CDKIs for cancer therapy, a more specific focus on the cellular activities of CDK4 and CDK6, which are activated by the oncogenic D-type cyclins, has recently achieved limited success $(47,48)$. Nonetheless, the major challenges of precise target specificity, rapidly acquired drug resistance, untoward toxicities in normal tissues, optimal patient selection (companion biomarkers) and efficient drug delivery remain.

\section{Cyclin G1, a non-canonical cyclin, opposes p53, the fragile 'guardian of the genome'}

Cyclin G1 is a non-canonical cyclin that i) structurally looks like a cyclin (cyclin box), ii) behaves like the earliest of all G1 cyclins (induction: G0-to-G1 boundary) and iii) physically targets a key regulatory enzyme $(\mathrm{Mdm} 2)$ to a critical checkpoint substrate (p53) in the executive regulation of the cell division cycle. While the observed growth-promoting function of human cyclin G1 is somewhat analogous to the progressive cyclin $\mathrm{D}, \mathrm{E}, \mathrm{A} / \mathrm{CDK} / \mathrm{pRb} / \mathrm{E} 2 \mathrm{~F}$ axis controlling cell cycle progression (Fig. 2), it is well-known that cyclin G1 operates via a separable and distinct regulatory pathway, namely the commanding cyclin G1/Mdm2/p53 axis, where precision targeted Ser/Thr phosphatase activity (i.e., cyclin G1-dependent Ser/Thr phosphatase activity) is intimately linked, through biochemical activation of the transforming protein of the MDM2 oncogene, to the commanding checkpoint control function(s) of the p53 tumor suppressor protein (Fig. 3).

The human cyclin G gene, now cyclin G1 or CCNG1 (49), was initially cloned by Hall et al at Children's Hospital Los Angeles (Los Angeles, CA, USA), where it was determined to be overexpressed in human osteosarcoma cells (50), providing the first of several important links to cancer. The observed 
overexpression of the cyclin G1 gene in human osteosarcoma, which remained constitutive throughout the cell division cycle in synchronized MG-63 cells, was rather perplexing, since murine cyclin $\mathrm{G}$ was identified in mice in a molecular screen for transcriptional targets of the p53 tumor suppressor, thereby (mistakenly) suggesting a growth-inhibitory function rather than a growth-promoting function for cyclin G1 (51). However, it was experimentally determined that the enforced overexpression of cyclin G1 in either normal or neoplastic cell lines did not cause the anticipated cell cycle arrest, nor did experimental overexpression of cyclin G1 induce apoptosis (51), as the p53 tumor suppressor (referred to as the molecular guardian of the genome and policeman of the oncogenes) is known to do under various conditions (52). By contrast, the ectopic overexpression of cyclin G1 is reported to promote the clonal expansion of normal human fibroblasts and to accelerate cell growth in RKO $\left(\mathrm{p} 53^{+}\right)$colon carcinoma cells (53), whereas the molecular suppression (or knockout) of cyclin G1 expression by antisense strategies was found to be uniformly lethal (54). These studies revealed an essential growth-promoting function for cyclin G1, thus identifying $C C N G 1$ as an accessible gene locus that may, through its suppression, demonstrably inhibit the growth of human tumor xenografts (upon intra-tumoral injection) in a nude mouse model of cancer $(55,56)$.

In 1995, Hall et al, in collaboration with E.M. Gordon, Medical Director of the Vector Production Unit, USC Gene Therapy Laboratories (Los Angeles, CA, USA) altered the focus of his research laboratory from the biochemistry of proline-directed protein kinases, CDK pathway characterization and related gene discovery to work together in translational research: Their goal was to develop a targeted and injectable gene delivery vehicle (vector) that would be efficient, effective and safe for repeated use in clinical practice. While their pioneering work on a tumor-targeted retrovector was progressing, Hall and Gordon utilized available retroviral vector-mediated gene transfer technologies to investigate functional knockouts of cyclin D1 (antisense CycD1) and cyclin G1 (antisense CycG1) in MG-63 osteosarcoma cells, in comparison with the enforced expression of $\mathrm{p} 21^{\mathrm{WAF} 1 / \mathrm{CIP} 1}$, a universal CDKI expressed in sense orientation (54). After examining the comparative experimental results in terms of both cytostatic (all three constructs inhibited cell proliferation) and cytocidal activities (i.e., TUNEL staining for overt apoptosis), Hall and Gordon focused on cyclin G1 knockouts for potential clinical development. At that time, this was a 'road less traveled' in terms of regulatory biology, which did indeed make a difference in the clinical setting.

\section{The commanding cyclin G1/Mdm2/p53 axis operating in normal and neoplastic cells}

A critical 'executor' element in the cyclin G1/Mdm2/p53 axis is the human homologue of the murine double minute gene 2 $(M d m 2)$ oncogene. Originally characterized as an amplified gene locus encoding a potent transforming (i.e., tumorigenic) oncoprotein in mice, the human $M d m 2$ gene was found to be amplified in numerous human cancers, including soft tissue sarcomas (20\%), osteosarcomas (16\%) and esophageal carcinomas $(13 \%)(57,58)$. More recently, links to the pathogenesis of breast cancer confirm that abnormally high levels of the
Mdm2 oncoprotein are detected in at least one-third (38\%) of human breast cancers, which cannot be explained by gene amplification alone (59). Shortly after its characterization, it was discovered that the Mdm2 oncoprotein forms a tight physical complex with the p53 tumor suppressor, thereby inhibiting p53-mediated transactivation events (60). In addition to inhibiting p53-dependent transcription, it was determined that the Mdm2 oncoprotein functions biochemically as a specific E3 ubiquitin ligase that is responsible for the ubiquitination and degradation of the p53 tumor suppressor protein (61). Thus, the Mdm2 oncoprotein antagonizes the p53 tumor suppressor on two levels: By ubiquitin-independent repression of p53 transactivation, and by ubiquitin-dependent proteolysis of the p53 protein (62), as seen in Fig. 3 (MOA II, tumor promotion).

This antagonistic association of the Mdm2 oncoprotein with p53 function and stability suggested that overexpression of the $M d m 2$ gene is yet another molecular mechanism, in addition to deletion or inactivating mutations in the TP53 gene per se, that may functionally inactivate the p53 tumor suppressor in the acquisitive process of neoplastic transformation. Therefore, it was reasoned that pharmaceutical agents targeting the Mdm2/p53 interaction in transformed cells retaining wild-type TP53 status may be a promising new approach to cancer therapy (63), which is considered particularly important in the context of hematological malignancies, where the frequency of TP53 mutations is relatively low (in comparison with solid tumors), while $M d m 2$ is frequently amplified and overexpressed (64). Pharmacological targeting of the pivotal Mdm2/p53 interaction with natural compounds, small molecules, and even stapled (helix-linked) peptides, has been extensively investigated in an effort to restore the tumor suppressor activity of wild-type p53 (65). Years of preclinical experimentation have identified promising drug candidates for further clinical evaluation; however, issues of drug-related toxicity and acquired resistance persist, and it was concluded that this particular class of compounds would definitely benefit from rational combinations with a second, potentially synergistic, pharmacological strategy (64).

In the elaboration of a pivotal Mdm2/p53 axis controlling both DNA-fidelity and cell fate, the oncogenic function of the non-canonical cyclin G1 was revealed: From a biochemical perspective, the critical functions of the Mdm2 oncoprotein, which is the major-negative regulator of p53, are intricately controlled by multiple site-specific protein phosphorylation events (66), thereby necessitating a site-specific Ser/Thr dephosphorylation event in order for the Mdm2 oncoprotein to be conformationally activated to carry out the destabilization of the p53. Moreover, this crucial Mdm2-activating dephosphorylation event was found to be cyclin G1-dependent. It was determined that the cyclin G1 protein forms a stable complex with the Ser/Thr protein phosphatase designated 2A (PP2A) $(67,68)$, specifically with the B'-class of regulatory subunits that determine both the substrate specificity and the subcellular localization of PP2A complexes (69). Conceptually, cyclin G1 binds tightly to the Mdm2 oncoprotein in vitro and in vivo, where it recruits $\mathrm{PP} 2 \mathrm{~A}$ to the $\mathrm{Mdm} 2$ oncoprotein, thereby stimulating the ability of the PP2A to dephosphorylate and activate $\mathrm{Mdm} 2$ at the critical regulatory site (68). In this capacity, cyclin G1 acts both as a targeting subunit and as a selectivity factor that stimulates and propels PP2A catalytic 


\section{Cyclin G1 expression: induction, neoplastic transformation, and "knockout"}


Figure 4. Cyclin G1 expression: Induction, neoplastic transformation and knockout. The characteristic induction of cyclin G1 protein (G0-to-G1 phase) is visualized by immunohistochemistry (A; brown staining) in the activated periphery (open arrows) and the proliferative smooth muscle cells (SMC; solid arrows) in a rat carotid artery model of vascular restenosis following balloon catheter injury. For comparison, the constitutively high levels of cyclin G1 expression seen in a flagrant pancreatic cancer xenograft (Tu), metastatic to the liver (A; insert) is contrasted by the negligible expression of cyclin $\mathrm{G} 1$ seen in the adjacent normal (host) nude mouse hepatocytes(h). The design of a dominant-negative (knockout) construct of cyclin G1 (p20 dnG1) is shown in the context of its MoMuLV retroviral expression vector (B); the truncated p $20 \mathrm{dnG} 1$ protein (devoid of $\mathrm{N}$-terminal and $\alpha 1, \alpha 2$ cyclin box domains) induces apoptosis in the presence of the abundant wild-type cyclin G1, as shown in western blots of cellular proteins (C).

activity toward Mdm2. The discovery that cyclin G1 associates physically with both PP2A and Mdm2 and, furthermore, that this physical association regulates the accumulation and degradation of the $\mathrm{p} 53$ protein (70), provides new and important insights into the oncogenic function of cyclin G1 and suggests that the main role of cyclin G1 may be to activate the Mdm2 oncoprotein to override the cell cycle checkpoint control functions of p53 (71). These findings provide a mechanistic explanation for the observation that cyclin G1 expression is associated with growth promotion rather than with growth arrest $(54,72)$. This conclusion is further supported by studies of genetic engineering in mice, where it was discovered that cyclin G1-deficient mice not only survive, but exhibit a reduced incidence of hepatic tumors upon exposure to hepatocarcinogens followed by partial hepatectomy (73). This decrease in tumor susceptibility associated with loss of cyclin G1 function is attributed to a resulting increase in p53 levels and a corresponding increase in p53 tumor suppressor activity (73). Taken together, these findings raise the possibility that the strategic modulation of cyclin G1 function in the commanding cyclin $\mathrm{G} 1 / \mathrm{Mdm} 2 / \mathrm{p} 53$ axis may be targeted at the molecular level for the development of novel anticancer agents.

\section{Targeting cyclin G1 function in experimental hyperplasia: Applications to cancer control}

Upon examining the role of cyclin G1 in normal proliferative cell populations, which exhibit normal levels of wild-type TP53 and Mdm2 gene expression, it was determined that downregulation of cyclin G1 (CCNG1) by retrovirus-mediated antisense gene transfer inhibits vascular smooth muscle cell proliferation and subsequent neointima formation (a form of hyperplasia) seen in rat carotid arteries following balloon catheter injury (74). Similar cytostatic and cytocidal effects of antisense cyclin G1 treatment were observed in proliferative cell populations of both rabbit keratocytes and human fetal lens epithelial cells (75). Immunohistochemical staining for cyclin G1 expression in balloon-injured arteries revealed a marked induction of gene expression, from non-detectable levels in quiescent arteries to relatively high levels of immunoreactivity in the proliferative neointimal masses (Fig. 4A). The inducible expression of cyclin G1 observed in vascular injury/restenosis is reminiscent of the marked induction of cyclin G1 in the regenerating liver following partial hepatectomy (76), rising rapidly from exceedingly low basal levels measured in the quiescent liver to appreciable steady-state levels. In contrast to the normally low levels seen in the liver, the expression of cyclin G1 in human tumor xenografts appears to be constitutively elevated (Fig. 4A).

Targeting cyclin G1 function with a dominant-negative (dnG1) mutant construct. After realizing that antisense 'knockdown' of cyclin G1 expression in normal and neoplastic cells was indeed informative and promising, yet reasoning that partial or incomplete suppression of CCNGl gene expression may still be problematic under physiological conditions (where enzymatic phosphotransferase rates are measured in msec and compensatory changes in gene expression are likely to occur), it was considered preferable to develop and deploy a 'dominant-negative mutant' construct of the cyclin G1 protein, the enforced expression of which would serve to counteract vital aspects of the cyclin G1 structure, binding and/or metabolism, thereby acting as a cyclin G1 antagonist, even in the presence of an abundance of the wild-type protein (Fig. 4B). 
Working with structural deletions and point mutations in the human cyclin G1 coding sequences, based on the homology of the repeating helical domains comprising what is referred to as the cyclin box, and the conserved amino acid residues predicted from crystallography to serve as contact points of the cyclin A/CDK2 complex $(49,50)$, an N-terminal deletion mutant was selected for development as the most potent negative-acting mutant of cyclin G1 (77). This dominant-negative mutant construct of human cyclin G1 (designated dnG1) is devoid of the extended $\mathrm{N}$-terminal domain proximal to the cyclin box domain, and is missing the first two helical segments ( $\alpha 1$ and $\alpha 2$ helices) of the cyclin box itself (Fig. 9).

\section{Development of a targeted retroviral vector to efficiently deliver the dnG1 'designer gene'}

The turn of the 21st century brought major biotechnological advances in the design and clinical applications of actively-targeted gene delivery vehicles, specifically pathotropic (disease-seeking) gene therapy vectors, which enabled the first systemically administered, tumor-targeted retroviral vectors to be validated in clinical medicine (78). While the gristly pathobiology of the tumor extracellular matrix (ECM), as well as the molecular mechanisms of retroviral vector-mediated gene transfer and expression, are beyond the scope of this focused review, the potential clinical implications of an 'active' tumor-targeted gene delivery vehicle are wide-ranging. Focusing on the abnormal collagenous proteins (i.e., lesion signature proteins) that are pathologically exposed during the process of tissue injury (such as balloon angioplasty), Hall and Gordon adaptively engineered a physiological surveillance function embodied within the complex structure of von Willebrand coagulation Factor (vWF), which normally guides platelets to sites of significant tissue injury, into the surface envelope protein (gp70) of the Moloney murine leukemia virus, thereby creating a desirable 'gain-of-function' (pathological-matrix-targeting), without impairing the natural receptor-mediated binding and entry of the targeted viral particles into target cells, thus preserving the efficiency of gene transfer $(79,80)$. Eventually, in anticipation of human gene therapy applications, the enabling tumor-targeting gain-of-function, first established in rodents, was genetically engineered into the 4070A 'amphotropic' murine leukemia virus envelope protein that is capable of transducing human cells $(81,82)$.

Armed with two powerful enabling biotechnologies, i) the matrix/lesion-targeted retrovector and ii) the cytocidal dominant-negative mutant construct of cyclin G1 (dnG1), validation of both targeted gene delivery and single-agent efficacy was demonstrated in preclinical studies of vascular restenosis, where significant long-term inhibition of neointima formation in balloon-injured rat arteries was observed $(77,83)$. This initial proof-of-concept was followed by preclinical studies on the safety and efficacy of the matrix/lesion-targeted vector bearing the inhibitory dnG1 construct (Mx-dnG1) applied as simple eye drops for the prevention of corneal haze induced by excimer laser-injury in rabbits (84). The encouraging results of this preclinical study prompted a formal evaluation of potential applications of anti-proliferative eye drops in humans by the NIH Recombinant DNA Advisory Committee (RAC), for a phase I/II intervention for superficial opacity/corneal scarring that occurs after phototherapeutic keratectomy (85). With these critical proofs-of-principle in hand (i.e., the efficacious preclinical management of experimental hyperplasia with Mx-dnG1), Hall and Gordon shifted their pioneering studies of lesion-targeted gene delivery to include the always pertinent and challenging models of metastatic cancer $(86,87)$ (Figs. 5-7), where the physiological obstacles to tumor-targeted gene delivery (dilution, filtration, turbulence, sheer forces, inactivation) remain paramount, and the clinical management of cancer cell growth, as well as the clinical management of tumor-angiogenesis, represents a major unmet medical need.

Important insights into the mechanisms and efficiencies of tumor-targeted gene delivery were gained from a liver model of metastatic cancer, wherein human MiaPaca2 pancreatic cancer cells were infused into the portal vein to establish tumors in nude mice (Fig. 5). In this model of regional gene delivery to established liver metastases, marker studies demonstrated an informative and selective targeting of cancer cells within the liver during the earliest stages of the metastatic process (Fig. 5A and C; left panel). Of note, this exquisite targeting of collagenous matrix signature proteins (i.e., biochemical footprints) left by invasive cancer cells, long before a discernable tumor is formed within the liver, has considerable implications in the diagnosis and treatment of human cancers. Later on, when flagrant tumors are formed within the liver and robust tumor angiogenesis is apparent, the tumor targeting extended to the tumor vasculature, where the proliferative endothelial cells are transduced by the vector, as demonstrated by $\beta$-galactosidase transgene expression (Fig. 5D-F; left panel). First and foremost, when the marker gene was replaced by dnG1, as in the cancer gene therapy vector (Mx-dnG1), dose-dependent tumor eradication was observed upon repeated intravenous infusions (86) (Fig. 5; right panel).

Prospective clinical trials for this regional approach to cancer gene therapy underwent formal review (and approval) for use in humans by the Food and Drug Administration (FDA)/RAC, a tumor site-specific phase I/II evaluation of the safety and efficacy of hepatic arterial infusion of a matrix-targeted retroviral vector bearing a dnG1 construct as treatment for colorectal carcinoma metastatic to the liver (88). However, at this point, Hall and Gordon opted instead to explore the even greater potential for systemic gene delivery (87), in light of the potential for more wide-ranging clinical applications in the treatment of metastatic cancers (Figs. 6-7).

In a classic nude mouse model of metastatic cancer (Fig. 6; left panel), it was observed that tumor-targeted gene delivery is not only conceivable (A and B vs. C), it is apparent (D and Evs.F); in addition, it is evident that the physiological partitioning of the circulating vector to tumors is dependent on the high-affinity matrix $(\mathrm{Mx})$-binding domain that was genetically transposed from the D2 module of the vWF propeptide into the primary structure of the retroviral envelope protein $(79-83,87)$. Notably, in order to accomplish tumor-targeted gene delivery within $1 \mathrm{~h}$, the matrix/lesion-targeted vector infused into the tail vein of the mice necessarily transited the heart, the lungs, and the heart once more, prior to entering the systemic circulation, including the blood vessels feeding the tumor xenografts (Fig. 6A and B; left panel), where it appears to spread out, similar to Coomassie blue dye in a natural sponge, as it physically contacts and effectively 


\section{Tumor targeting in a liver model of metastatic cancer}

Targeting cancer cells and vasculature

Portal vein infusions of the targeted vector bearing a $\beta$-gal marker gene
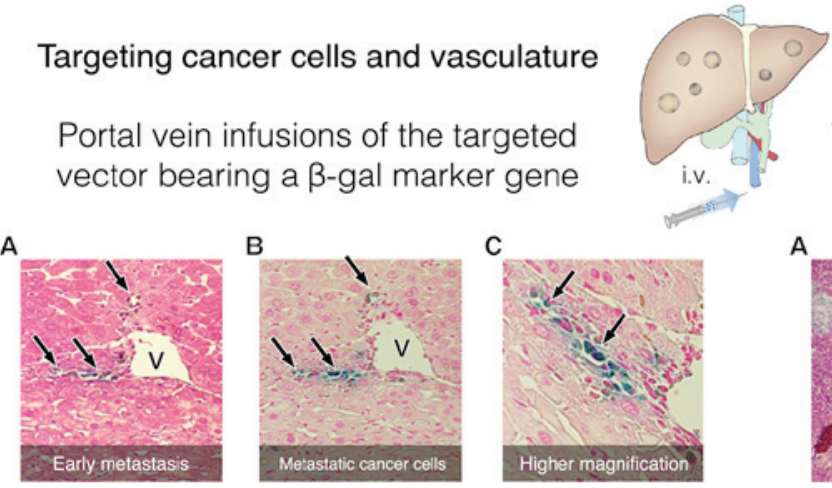

D



H\&E stain
C

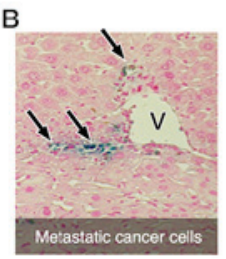

E

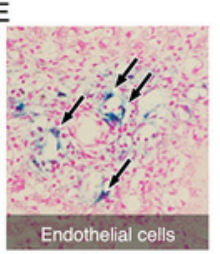

$\beta$-galactosidase (transgene)

$\mathbf{F}$
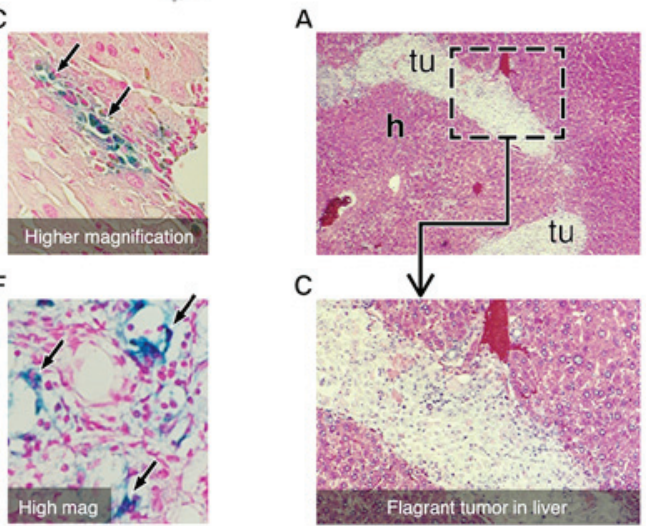

Untreated PBS control
Mx-dnG1-mediated tumor destruction

Tumor eradication following repeated portal vein infusions of targeted Mx-dnG1

Figure 5. Regional delivery of the matrix/lesion targeted vector to the liver via the portal vein. Early metastasis (left plate A-C: A, H\&E staining); detection of the $\beta$-galactosidase transgene (B and $\mathrm{C}$ ) in metastatic tumor cells (arrows). Tumor angiogenesis (left plate D-F: D, H\&E stain); detection of the $\beta$-gal transgene ( $\mathrm{E}$ and F) in proliferative vascular endothelial cells (arrows). Flagrant tumors (right plate A, C magnified) of untreated control animals is shown in contrast to the dose-dependent Reduction of tumor foci (right plate B, D magnified) achieved by repeated portal vein infusions of the cytocidal Mx-dnG1 vector. Note: The residual immune infiltrates (B arrows, D golden cells magnified) are hemosiderin-laden Kupffer cells engaged in the elimination of residual tumor debris.

\section{Tumor-targeted vector enables efficient gene delivery to tumors by i.v. infusion}

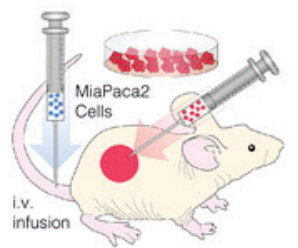

Nude mouse model of

metastatic cancer

Seeking ECM-signature proteins, the targeted vector accumulates rapidly $(A, B)$ and delivers transgenes efficiently $(D, E)$ to tumors.

A

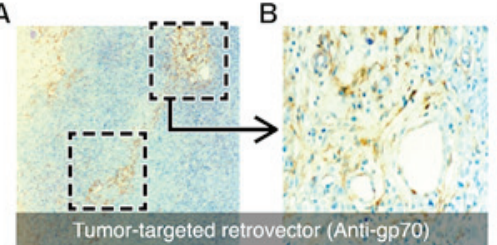

D

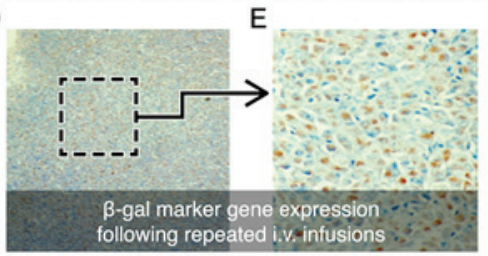

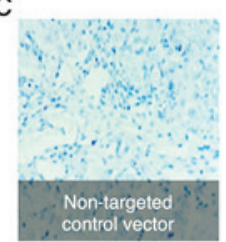

$\mathrm{F}$

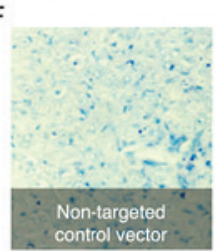

Rexin-G (dnG1) vector induces apoptosis in subcutaneous human cancer xenografts

A
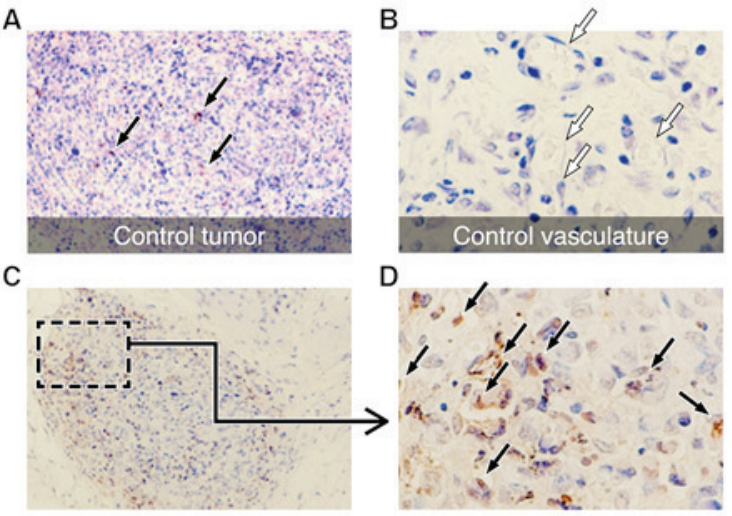

E


Figure 6. Left panel: Depicts tumor-targeted vector delivery (A, B magnified vs. C control) and subsequent $\beta$-gal transgene expression (D, E magnified vs. F control) following repeated intravenous vector infusions in a subcutaneous xenograft model of metastatic pancreatic cancer. Right panel: Massive apoptosis (arrows: C and D, high mag; E, stroma; F, necrosis) in association with anti-angiogenesis and focal necrosis, compared with control tumors (A, B magnified) where angiogenesis is robust and apoptosis rare.

transduces proliferative tumor cells with a $\beta$-galactosidase marker gene (Fig. 6D and E; left panel).

When the marker gene was replaced with the inhibitory dnG1 construct (Fig. 6; right panel), it was confirmed that the cytocidal mechanism of action of $\mathrm{dnG} 1$, as observed in both hyperplastic lesions and cancerous xenografts, is attributed to the activation of DNA fragmentation via the process of apoptosis. This pioneering study demonstrated that the $\mathrm{Mx} /$ lesion-targeted dnG1 retroviral vector $(\mathrm{Mx}-\mathrm{dnG}$ ) deployed by peripheral vein injection i) accumulates rapidly in 


\section{Control tumors exhibit robust growth, cell proliferation, and neo-angiogenesis}

\author{
Mx-dnG1 infusions alter tumor histology
}

Focal necrosis, anti-angiogenesis, fibrosis
Untreated tumors: H\&E stain

A

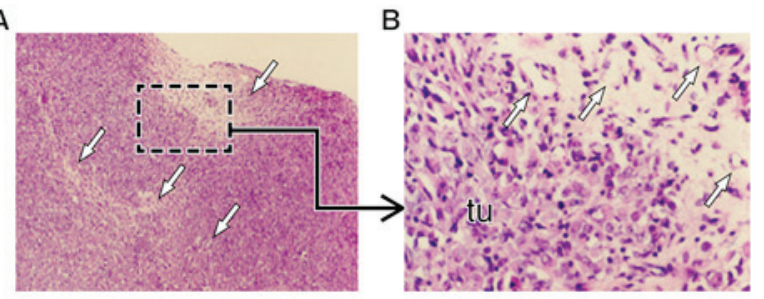

Untreated tumors: Trichrome stain

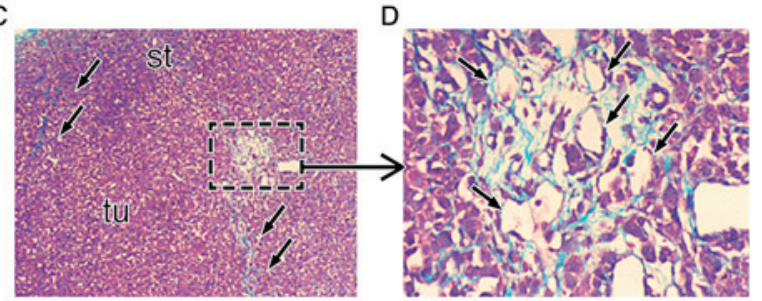

Mx-dnG1 tumors: H\&E stain

A



Mx-dnG1 tumors: Trichrome stain

C

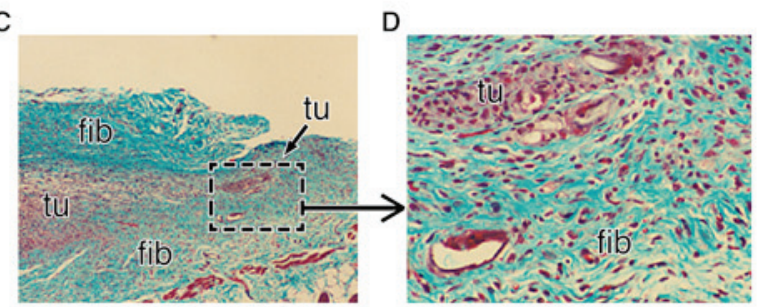

Figure 7. Characteristic changes in tumor histology following intravenous Mx-dnG1 treatment. Untreated tumor xenografts (left panel) exhibit robust tumor (tu) cell proliferation with active zones of neo-angiogenesis (A, open arrows; B, magnified); Masson's trichrome stain (C, D magnified) reveals exposed collagenous proteins (solid arrows, blue stain) associated primarily with angiogenesis and reactive stroma formation (st). By contrast, Mx-dnG1 treatment (right panel) reduces the flagrant population of proliferative tumor cells (tu) significantly (A, boxed; B, magnified), producing large regions of focal necrosis (nec) accompanied by overt anti-angiogenesis $\left(^{*}\right)$. Residual tumors are ultimately reduced to besieged clusters of proliferative tumor (tu) cells $(\mathrm{C}$, boxed; D, magnified), as reactive/reparative fibrosis (fib), including nascent (i.e., targetable) ECM deposition (blue stain), dominates the histology of tumor regression observed in Mx-dnG1 treated animals.

tumor vasculature, ii) transduces tumor cells with exceedingly high-level efficiency and iii) enables demonstrable therapeutic gene delivery and long-term efficacy of dnG1 without eliciting appreciable toxicity (87). In addition to the marked apoptosis observed in Mx-dnG1 treated tumors (Fig. 6; right panel), characteristic histological changes in tumors after repeated systemic administration includes: Zones of focal necrosis, overt anti-angiogenesis and reparative fibrosis accompanied by ECM deposition, which occupies an increasingly greater proportion of the residual tumor, as the cancer cells and the proliferative tumor vasculature are eradicated progressively by the repeated intravenous infusions of Mx-dnG1 (Fig. 7; left panel A-D control tumors vs. right panel A-D treated tumors).

Following the establishment of three preclinical proofs of principle, namely that i) tumor-targeted gene therapy is feasible via simple intravenous infusions, ii) tumor-targeted delivery of the dnG1 'killer gene', which exhibits both anti-angiogenic and anti-tumor activities, is capable of altering the course of metastatic pancreatic cancer, an otherwise fatal disease and iii) the design features and general safety profile of the first targeted, injectable gene therapy vector had been critically evaluated by the FDA/RAC and formally approved for clinical use in humans, the first clinical studies were initiated.

\section{Clinical studies demonstrate broad-spectrum anticancer activity and single-agent efficacy}

In 2003, a clinical-grade retroviral expression vector bearing an inhibitory dnG1 construct of the cyclin G1 gene (designated Rexin-G) became the world's first targeted, injectable vector to be approved for clinical trials in the treatment of intractable metastatic disease. Uniquely suited, by design, to perform this tumor-targeting function within the context of the human circulatory system, Mx-dnG1 (aka Rexin-G) is a pathotropic (disease-seeking) gene delivery vehicle bearing the dnG1 'killer' gene, a therapeutic tumor-targeted nanoparticle that selectively seeks out and accumulates in metastatic lesions upon simple intravenous infusion. Preclinical validation of tumor-targeted gene delivery, accompanied by critical demonstrations of dose-dependent efficacy in pertinent cancer models, was followed by the first clinical studies, which aimed to demonstrate the potential for achieving broad-spectrum, single-agent, anticancer efficacy in the clinic. A summary of completed clinical studies is shown in Table I.

As with all targeted biologics, a major objective was to assess and establish the clinical safety of the vector system, while progressively seeking efficacy within the rule-based designs and dose escalation protocols used in phase I cancer clinical trials (89). Cooperative (US FDA sanctioned/BFAD-approved) international studies conducted in the Philippines enabled stepwise intra-patient dose escalations, thereby achieving clinical dose-dependent efficacy in an expedient manner $(90,91)$, while the US FDA required more traditional studies of potential dose-limiting toxicities (DLT) and/or cumulative toxicities to be conducted at sub-therapeutic doses (92) before a formal determination of adequate safety would enable a progressive stepwise dose escalation. When clinical significant dose-dependent efficacy was demonstrated in US-based phase I/II studies of intravenous Rexin-G for advanced sarcoma and osteosarcoma (93-95), including 
Table I. Clinical studies evaluating repeated intravenous infusions of a pathotropic Mx-dnG1 retrovector (Rexin-G) as monotherapy for chemoresistant metastatic cancer.

\begin{tabular}{|c|c|c|c|}
\hline Completed studies & Types of cancer treated & Description of results, conclusions & (Refs.) \\
\hline $\begin{array}{l}\text { International phase I/II } \\
\text { protocols for pancreatic } \\
\text { cancer are expanded to } \\
\text { include all solid tumors }\end{array}$ & $\begin{array}{l}\text { Advanced pancreatic cancer, expanded } \\
\text { to include metastatic melanoma, } \\
\text { breast, uterus, colon cancer, } \\
\text { and leiomyosarcoma }\end{array}$ & $\begin{array}{l}\text { Demonstrations of overall safety, } \\
\text { lack of toxicity, and potential for } \\
\text { clinical efficacy is established; a } \\
\text { dose-response calculus is advanced }\end{array}$ & $(90,91)$ \\
\hline $\begin{array}{l}\text { Phase I (USA) low-dose } \\
\text { safety study in advanced } \\
\text { or metastatic pancreatic } \mathrm{Ca}\end{array}$ & Advanced pancreatic cancer & $\begin{array}{l}\text { General safety is confirmed; no RCR } \\
\text { no inactivating antibodies; no DLT, } \\
\text { enabled further dose escalation(s) }\end{array}$ & $(92)$ \\
\hline $\begin{array}{l}\text { Phase I/II dose escalation } \\
\text { studies of safety and efficacy }\end{array}$ & $\begin{array}{l}\text { Chemotherapy-resistant sarcoma, } \\
\text { breast cancer and pancreatic cancer }\end{array}$ & $\begin{array}{l}\text { Demonstrates significant anticancer } \\
\text { activity (efficacy) without toxicity }\end{array}$ & $(93,94)$ \\
\hline $\begin{array}{l}\text { Phase I/II with advanced } \\
\text { phase II study of resistant } \\
\text { sarcoma and osteosarcoma }\end{array}$ & $\begin{array}{l}\text { Chemotherapy-resistant sarcoma } \\
\text { and osteosarcoma }\end{array}$ & $\begin{array}{l}\text { Safety and dose-dependent clinical } \\
\text { efficacy is demonstrated; } \\
\text { significant improvements } \\
\text { in overall survival }\end{array}$ & $(95,96)$ \\
\hline $\begin{array}{l}\text { Advanced phase I/II study } \\
\text { of chemotherapy-resistant } \\
\text { metastatic pancreatic Ca }\end{array}$ & Advanced pancreatic cancer & $\begin{array}{l}\text { Safety and dose-dependent clinical } \\
\text { efficacy is demonstrated; } \\
\text { significant improvements in } \\
\text { overall survival }\end{array}$ & $(97)$ \\
\hline
\end{tabular}

significant improvements in both progression-free and overall survival, the FDA approved an 'across-the-board' dose escalation allowance (applicable to all ongoing trials), thereby enabling these higher, more efficacious doses (i.e., optimal biological doses) to also be administered to breast and pancreatic cancer patients (96-98).

From these clinical studies, including the physiological dose-response kinetics, a predictive pharmacology of tumor-targeted genetic medicine began to emerge: A calculus of parity (or therapeutic equivalence) was introduced, in which the metastatic tumor burden of a given patient is evaluated and used in calculations, including vector targeting efficiencies and performance, in determining the effective intravenous dose(s) required to achieve tumor eradication (91). Advancements in bioprocess development enabled high-potency clinical grade vectors, which further simplified intravenous infusions and led to the accelerated approval of Rexin-G for all solid tumors by the Philippine FDA in 2007. This was followed by a rapid progression of clinical studies in the US, where Rexin-G received several Orphan Drug designations, including FDA Fast-Track status for metastatic pancreatic cancer, which stands at the cusp of phase III clinical trials $(97,98)$. Long-term follow-up of an advanced phase I/II study using Rexin-G for chemotherapy-resistant sarcomas revealed the clinical value of the observed Rexin-G (dnG1) dose-response relationships in terms of overall patient survival: The 1-year survival rate increased from $0 \%$ at dose level I to $28.5 \%$ at dose level II-III, to an impressive $38.5 \%$ at dose level IV-V (with $31 \%$ of the patients alive at 2 years) following initiation of Rexin- $\mathrm{G}$ monotherapy, which may be considered as a gold standard in terms of objective clinical responses (96-98).

At the time of this review, Rexin-G had been administered safely to $>270$ patients worldwide, including $>3,000$ total intravenous infusions without serious side effects, vector issues, inactivating antibodies, or DLT. Documentation of significant anticancer activity, single-agent efficacy and objective clinical responses (including evidentiary histology), have been reported in a broad spectrum of cancers derived from all three germ layers (98-100). Clinical confirmation of i) tumor-targeted gene delivery, ii) a pro-apoptotic dnG1 mechanism of action and iii) characteristic changes in tumor histology (originally observed in preclinical models) are clearly recapitulated in the clinical setting, as is clearly seen in an opportunistic surgical (liver) biopsy obtained from a metastatic pancreatic cancer patient undergoing intravenous Rexin-G treatment (Fig. 8). In addition to statistically significant increases in patient survival, a considerable number of advanced-stage, chemotherapy-resistant cancer patients treated with repeated infusions of Rexin- $G$ as monotherapy, including metastatic breast cancer, pancreatic cancer, malignant melanoma, osteosarcoma and soft tissue sarcoma patients, remain cancer-free or without active disease progression $\geq 9-12$ years after the initiation of Rexin- $G$ treatment (101).

\section{Restoring long-lost tumor suppression with a dominant-negative cyclin-G1 antagonist}

Strong support for the proposed growth-promoting function of cyclin G1 in the commanding cyclin G1/Mdm2/P53 axis came from functional genomics, which identified microRNAs (miRNAs) as a new class of endogenously expressed, small non-coding gene-regulatory RNA molecules that interact with the p53 transcription factor and its network of effectors at multiple levels $(102,103)$, thereby impacting both the mechanics of cell cycle progression and the fate of proliferative cells. High-throughput screens investigating the role of miRNAs in the pathogenesis of human HCC identified miR-122 as the most predominant species of hepatic regulatory miRNA, which is 
Targeted gene delivery in the clinic Accumulations of vector-particles in tumor biopsy

A

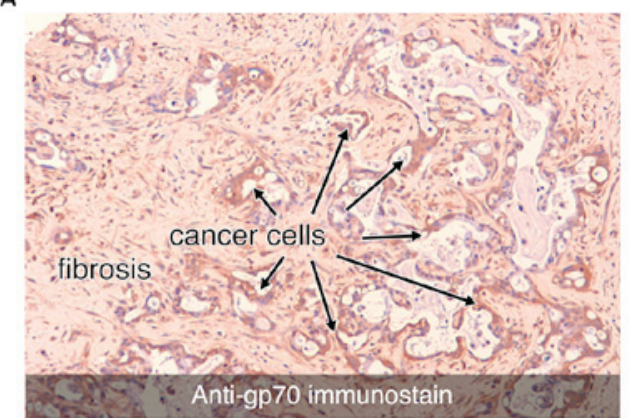

B



C

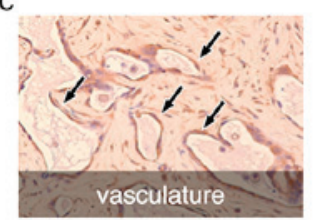

Mechanisms of Rexin-G (dnG1) action: apoptosis, anti-angiogenesis, reparative fibrosis

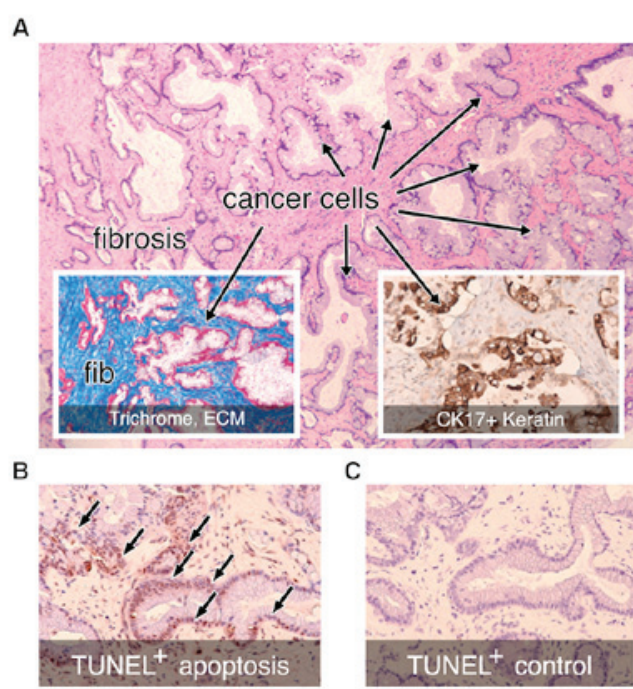

Figure 8. Histochemical analysis of a tumor biopsy: Pancreatic cancer, metastatic to the liver, following intravenous infusions of tumor-targeted Mx-dnG1 (Rexin-G). Left panel, tumor targeting: Immunohistochemical staining for the retrovector gp70 envelope protein (brown staining) demonstrates widespread vector penetration and accumulation within the tumor (A), with particularly high levels of immunostaining appearing in the cancer cells (A and B, arrows) and associated vasculature (C, arrows). Right panel, mechanisms of action: (A) Clusters of residual (CK $17^{+}$) pancreatic cancer cells (A, inset of western blot) are distinguished from the reactive fibrosis (fib; A, inset) seen with Masson's trichrome stain, which stains the collagenous extracellular matrix proteins bright blue. Application of the TUNEL method for detecting apoptotic DNA fragmentation reveals massive levels of apoptosis (arrows) in cancer cells (B vs. C, control) as the actual mechanism of dnG1 action.

either lost or severely downregulated in $\sim 70 \%$ of HCC cancers and in all HCC-derived cell lines (104). These studies identified cyclin $\mathrm{G} 1$ as a primary target of miR-122 suppression, which accounts for the inverse correlation between miR-122 and high levels of cyclin G1 expression observed in primary liver carcinomas. Loss of miR-122 expression in liver cancer correlates with a poor prognosis indicative of tumor progression, including a notable gain in invasive metastatic properties (105). As depicted in Fig. 3, miR-122 regulates p53 protein through cyclin G1 in HCC cells (106): The miR-122/cyclin G1 interaction modulates p53 protein stability and transcriptional activity. Accordingly, enforced/restored expression of miR-122 decreases cell viability (107) and induces cell cycle arrest and apoptosis in HCC cell lines (108).

Important insights into the natural tumor suppressor function of miR-122 were gained from genetic engineering, where it was determined that miR-122 gene knockout mice are prone to hepatic tumor development, while AAV-mediated delivery of miR-122 to the livers of such mice inhibits tumorigenesis (109). By repressing the expression of cyclin G1 (CCNG1 transcription), miR-122 increases p53 protein levels and suppressor activity and inhibits tumorigenesis in liver cancer models. Insights into the proto-oncogenic function of cyclin G1 were gleaned from studies of HBV subversion in HCC (110), where it was determined that the HBx-protein directly mediates suppression of miR-122 expression and enhances hepatoblastoma cell proliferation through the functional modulation of the cyclin G1/Mdm2/p53 axis; i.e., downregulation of the expression of the tumor suppressive miR-122 increases cyclin G1 expression, which in turn abolishes p53-mediated suppression of HBV replication and promotes hepatocellular proliferation (Fig. 9; MOA III viral subversion). Thus, it appears that the inhibitory dnG1 expression construct described herein, by counteracting the oncogenic function(s) of cyclin G1, is capable of restoring a lost, missing, or deregulated axis of tumor growth/suppression, which operates by triggering an endogenous apoptotic mechanism of action, in the presence or absence of p53.

\section{Cyclin G1 proto-oncogene promotes cell survival and progression over DNA fidelity}

The establishment of cyclin G1 (CCNG1) as a bona fide proto-oncogene and a powerful growth-promoting protein has profound implications for the clinical staging, prognosis and management of human cancers. Normally induced in response to tissue injury (G0/G1 boundary), as in hyperplasia (Fig. 4), cyclin G1 is frequently overexpressed in human breast and prostate cancers (111), osteosarcomas, colorectal cancers (112) and HCC (113), wherein CCNG1 overexpression is clearly correlated with a poor prognosis. As mentioned above, CCNG1-null mice survive and even exhibit decreased incidence, size and malignancy of tumors due to the resulting dominance of DNA-sensing p53-dependent tumor suppressor functions (73); however, in proliferative populations of tumor cells, including tumor neovasculature, the blockade of cyclin G1 expression or function is uniformly lethal. This apparent dependence of cancer cells on sustained cyclin G1 expression for cell survival, which is acquired during the course of diverse multistage carcinogenesis, is referred to as 'oncogene addiction' (114); indeed, this acquired state of dependency on cyclin G1 identifies $C C N G 1$ as a vulnerable locus in human cancers, which can be targeted on several levels to gain a positive therapeutic advantage. 
MOA III. Viral subversion

Hbx targets miR-122, elevates Cyclin G1



MOA IV. Cancer gene therapy

Anatomy of a dnG1 'killer' gene product

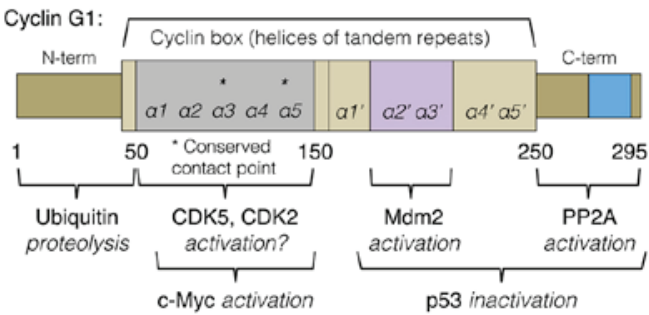

Dominant-negative mutant

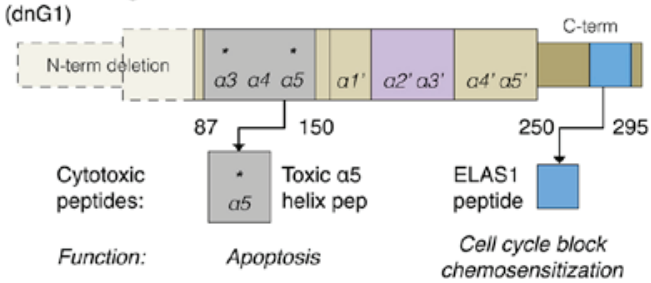

Figure 9. Left panel: Mechanism-of-action (MOA) III. HBx-mediated viral subversion of the hepatocellular division cycle operates by suppression of miR-122, hence de-repression of CCNG1 expression. Right panel: MOA IV. Cancer gene therapy, dng1 structure. The cytocidal dnG1 protein, a dominant-negative mutant construct of cyclin G1, is devoid of the 'ubiquitinated' N-terminus (proteolytic processing), as well as the first two helical segments ( $\alpha 1$ and $\alpha 2$ ) of the definitive cyclin box, characteristically arrayed in cyclins as a tandem set of helical segments, including two highly-conserved residues (asterisks) essential for cyclin-dependent kinase (CDK) binding. The cytocidal dnG1 protein, which induces apoptosis in proliferative cells, retains the presumptive (?) CDK contact points (Helix $\alpha 3^{*}, \alpha 5^{*}$ ) and the structural domains attributed to PP2A, $\beta^{\prime}$ and Mdm2 binding. Remarkably, new therapeutic peptides (e.g., ELAS1 and $\alpha 5$ Helix peptides) derived from structures or homologous interfaces contained within the dnG1 protein are reported to induce cell cycle blockade and apoptosis, respectively.

Examination of the structure of cyclin G1 provides conceptual insights as to its multiplex biochemical functions (Fig. 9; MOA IV, right panel). The cyclin G1 protein is an unusually unstable protein, exhibiting a half-life of 20 min; this instability is attributed to ubiquitin-mediated proteolysis involving the extreme N-terminus of the protein (115). The homology between cyclin G1 and known regulatory cyclins suggests that cyclin G1 may activate one or more CDK partners under certain conditions. Indeed, cyclin G1 is capable of physically interacting with CDK1,2, 4, 5 and 6, the kinase activity of which appears to contribute physiologically to the short half-life of the cyclin G1 protein (116). However, neither Histone H1- nor Rb-kinase activity was detected in cyclin G1/CDK2 immunoprecipitates (116), suggesting that cyclin G1 association with a specific CDK partner, as well as the resulting CDK activity, may be more tightly regulated by additional factors and/or is uniquely targeted to one or more undetermined protein substrates. Subsequently, convincing aspects of cyclin G1 function in direct association with CDK 5 have been revealed: Activation of CDK 5 by cyclin G1 binding physically targets the active kinase complex to the c-Myc oncoprotein, the overexpression of which immortalizes cells, reduces growth factor requirements, promotes cell cycle progression and inhibits cell differentiation (117). The resulting cyclin G1/CDK5 phosphorylation of c-Myc on Ser-62 (-X-Ser ${ }^{62}$-Pro-X-) stabilizes the multifunctional transcription factor, resulting in transcriptional activation of a defined (E-Box-containing) set of growth-promoting genes, including both cyclins and CDKs, which are capable of driving cell proliferation (118). Mechanistically, $c-M y c$ is a critical platelet-derived growth factor-inducible 'competence gene' that activates diverse cellular processes associated with entry and progression through the cell cycle, including the synthesis of cellular components in preparation for cell division. In this manner, by activating and selectively targeting CDK5 kinase activity to activate and stabilize the c-Myc oncoprotein, the overexpression of cyclin G1 enables cancer cells to overcome radiation-induced (i.e., DNA-damage-induced) cell cycle arrest (117). Although the transcriptional targets of c-Myc include a number of DNA repair genes, thereby coupling DNA replication to the pathways and processes that preserve the integrity of the genome (118), the net effect of cyclin G1 function in association with CDK5 (or CDK2) is to abrogate DNA-fidelity checkpoint controls to promote cell survival, cell competence and cell cycle progression at the peril of increasing error-prone DNA synthesis, as is often found in cancers.

Significant clues into the function of cyclin G1/CDK complexes as a 'survival factor' were obtained in the nervous system, where cyclin G1 expression was induced by nerve injury in mature (post-mitotic) motor neurons and remained elevated during the early stages of nerve regeneration along with other 'immediate-early' genes associated with cell survival (119), suggesting that cyclin G1 functions as a survival factor in post-mitotic neurons, maintaining cell viability during the process of tissue repair. Following this mechanistic insight, we find that mild cognitive impairment, a transitional disease state that precedes more serious neurodegenerative problems associated with Alzheimer's disease (AD), is accompanied by increased co-expression of cyclin G1, CDK2 and CDK5 in afflicted brain regions (120). This is in keeping with the theory that neuronal cell death associated with AD has, as its root cause, an ectopic re-entrance into the cell cycle (121), which results in the hyperphosphorylation of microtubule-associated tau proteins characteristic 
of AD neurofibrillary tangles. Various neurotoxic insults induce hyperactivation of CDK5, with fatal consequences for the cell (122). On the other hand, lack of CDK5 activity results in neuronal cell death (123), suggesting that precise control of CDK5 activity is crucial for neuron survival via the site-specific phosphorylation of the apoptosis inhibitor Bcl-2 (124). Apart from cyclin G1/CDK5 complexes, which target and activate the $c-M y c$ competence gene in cancer cells (117), a brain-specific regulatory subunit of CDK5 has been identified as p35, the N-terminal truncation of which (from p35 to p25) causes prolonged activation of CDK5, mis-localization and pathological phosphorylation of substrates; i.e., the p25/Cdk5 kinase hyperphosphorylates tau, disrupts the cytoskeleton and promotes cell death by apoptosis in primary neurons $(122,125)$. In this same manner in which the proteolytic truncation (N-terminal deletion) of this p35 CDK5-activator protein converts the p35/CDK5 kinase complex from a survival factor to a cytotoxic p25/CDK5 kinase activity that promotes cell death by apoptosis in neurons, the 'designer' N-terminal truncation of cyclin G1 into a dnG1 mutant protein (Fig. 9) converts the survival functions (i.e., anti-apoptotic, pro-survival) of the CCNG1 oncogene (mediated via cyclin G1/CDK5-dependent c-Myc activation) into the pro-apoptotic, cytocidal functions of the truncated mutant dnG1 'killer' gene. In this case, a potent proteolytically stable antagonist of wild-type CCNG1 gene function is generated.

A note to future biomedical researchers. While the functionality of cyclin G1 in the nervous system is beyond the scope of this oncological review (cancer cells are constitutively competent), this mechanistic link to cell survival and proliferative competence has important implications in terms of artificially/therapeutically promoting nerve regeneration and associated tissue repair, in light of the striking potentiality for tail and/or limb regeneration that is evident in lower vertebrates.

Whereas the early induction of cyclin G1 observed as cells exit from quiescence (G0-to-G1 transition) in experimental models of hyperplasia and liver regeneration is indicative of its role in establishing cellular competence to proliferate, the putative CDK kinase partner would thereby represent a G0/G1 competence-promoting factor $(\mathrm{CPF})$, perfectly analogous to SPF and MPF. The target substrate for this cyclin G1-dependent kinase activity, CDK5 and/or possibly CDK2, $(116,120)$ is the $c-M y c$ oncogene, the activation of which is associated with the start of cellular proliferation, cell cycle progression, increased genomic instability, reduced adhesion, EMT, tumor invasion and metastasis. The overexpression of $c-M y c$ in $~ 50 \%$ of human cancers correlates with poor patient survival (126), while c-Myc is often considered to be among the most desirable cancer targets, although it appears to be among the most 'undruggable' of molecular targets in all of cancer therapy (127).

In addition to i) promoting cell growth and survival as an enzymatic cyclin G1/CDK5 (or cyclin G1/CDK2) CPF in reparative tissues, and ii) disabling p53 checkpoint control via the cyclin-G1/Mdm2/p53 axis, resulting in error-prone DNA-synthesis that is characteristic of an advanced metastatic state, a cyclin-G1-dependent pathway also appears to mediate the troublesome EMT, which characteristically results in a more aggressive, invasive cancer phenotype (observed in distant metastases) and, hence, a worsening prognosis (113). Recently, CCNG1 was found to be amplified in a particularly aggressive subset of triple-negative breast cancer (TNBC) cells and in patients with chemotherapy-resistant TNBC, in which cyclin G1 overexpression was directly linked to the molecular mechanisms regulating both polyploidization and chemotherapy resistance (128): Upon paclitaxel exposure, the pro-survival function of cyclin G1 promotes breast cancer cell survival by inducing polyploidy, thereby limiting treatment options and outcomes involving taxanes, yet further validating cyclin G1 as a strategic target for medical intervention in the treatment of advanced metastatic breast cancer (Table I).

\section{Combinatorial approaches and companion diagnostics for CCNG1 targeted therapies}

Dysregulation of cyclin G1 is the driving oncogenic event in a large number of human cancers. By restoring a critical locus of CCNG1 suppression, the enforced expression of miR-122, as well as cyclin G1 silencing, suppresses tumor growth and increases the sensitivity of HCC cells to doxorubicin (DOX) (106); thus, exciting new possibilities for combinatorial therapies are emerging. Indeed, cyclin G1 expression regulates and determines the outcome of taxane chemotherapy: Elevated cyclin G1 expression accompanies paclitaxel (PTX) -induced mitotic arrest and promotes cancer cell survival after PTX exposure, whereas cyclin G1 depletion by RNA interference delays mitotic slippage and enhances paclitaxel-induced apoptosis (129), providing molecular insights to guide future combinatorial treatment options. Moreover, additional insights into the molecular mechanisms of chemotherapeutic drug resistance have recently been uncovered: It was recently reported that $\operatorname{miR}-27 \mathrm{~b}$, a novel miRNA that regulates multidrug resistance (MDR) in gastric cancer, targets and suppresses $C C N G 1$ expression and restores p53-dependent checkpoint activities. Ectopic expression of miR-27b increases the chemosensitivity of gastric cancer cells to several chemotherapeutic drugs by inhibiting CCNG1 (130). Likewise, ectopic expression of the tumor-suppressive miR-23b, which is downregulated in colon cancer and potently mediates multiple steps of metastasis, including tumor growth, invasion and angiogenesis, selectively targets CCNG1 for suppression (131): By binding with the 3' untranslated region of CCNG1, miR-23b downregulates cyclin G1 mRNA and protein expression, thereby inhibiting ovarian tumorigenesis and cancer progression (132). A variety of molecular approaches targeting cyclin G1 expression and/or function for cancer control are shown in Table II.

Establishment of the once-paradoxical cyclin G1 proto-oncogene as a dominant, growth-promoting, potentially cancer-causing component of the commanding cyclin G1/Mdm2/p53 axis has enormous implications in terms of the future of clinical medicine, including cancer diagnostics, prognostics, and the potential for rational combinatorial therapies. The frequency of cyclin G1 overexpression observed in human cancers, as well as the newfound association to the molecular mechanisms of cancer metastasis (EMT) and 
Table II. Medical intervention via targeting cyclin G1 (CCNG1) for cancer therapy.

Modes of medical intervention

Mx-dnG1 (Rexin-G): Dominant-negative mutant construct of cyclin G1 (dnG1) delivered intravenously by means of a tumor-targeted retroviral expression vector CCNG1-suppressive oligonucleotides:

- CCNG1 antisense fragments:

- Suppressive RNA, miR 122:

- siRNA-mediated CCNG1 knockdown:

- Suppressive RNA, miR-27b

- Suppressive RNA, miR-23b

Cytotoxic peptide drugs:

- ELAS1 peptide (cyclin G1 C-terminus):

- Toxic a5 Helix peptides (cyclin box):
Description of mechanisms, efficacy, conclusions

(Refs.)

$\sqrt{ }$ Apoptosis of transduced cancer cells

(90-101)

$\sqrt{ }$ Potent tumor anti-angiogenic activity

$\sqrt{ }$ Broad spectrum antitumor activity

$\sqrt{ }$ Single-agent efficacy, long-term survivors

Suppression of cyclin G1 protein expression

$\sqrt{ }$ Induces apoptosis in cancer cells, tumors

$\sqrt{ }$ Induces apoptosis in cancer cells, tumors;

$\sqrt{ }$ Increases sensitivity to DOX via apoptosis;

$\sqrt{ }$ Inhibits cell invasion/metastatic phenotype

$\sqrt{ }$ CCNG1 depletion enhances taxane toxicity

$\sqrt{ }$ Regulates multidrug resistance in gastric $\mathrm{Ca}$.

$\sqrt{ }$ Induces apoptosis, suppresses tumorigenesis, cancer progression and metastasis

$\sqrt{ }$ Induces apoptosis, CPT chemosensitization

$\sqrt{ }$ Induces apoptosis, necrosis, antitumor action chemotherapy resistance, provide new avenues for patient profiling, staging and treatment, including chemosensitization by strategic targeting of cyclin G1 as a locus of diagnostic evaluation and clinical control. The advent of the injectable, tumor-targeted vector and its demonstrated safety in clinical trials, enables physicians of the future to think and to reach beyond previous limitations in clinical trial designs. The development of Mx-dnG1 (Rexin-G), which, by itself, induces apoptosis in cancer cells and tumor-associated vasculature (in the presence or absence of p53), is a powerful clinical tool in terms of applied cell cycle checkpoint control, which merits conscientious clinical development. Indeed, the functional characterization of discrete structural domains that are present within the cytocidal dnG1 have recently identified the ELAS1 peptide, which is based on a conserved sequence motif within the extended C-terminal domain of cyclin G1, as a therapeutically useful peptide drug (133). Reportedly, the ELAS1 peptide, which competitively blocks the physical association of cyclin G1 with the B' $\gamma$ subunit of PP2A, sensitizes osteosarcoma cells to camptothecin and irinotecan, and induces apoptotic death in both prostate adenocarcinoma and squamous cell carcinoma, albeit in a wild-type TS53-dependent manner. By comparison, the ability of dnG1 to activate apoptosis in the presence (hyperplasia, neoangiogenesis) or absence (most metastatic cancer cells) of wild-type p53 predicates structure-function relationships involving programmed cell death, which remained to be identified within the truncated $\alpha$-helices (molecular interfaces) of the dnG1 cyclin box domain.

Further elaboration of the structure-function relationships of the cyclin box (134), which provide a mechanistic link to cell death/signaling mechanisms, came from screening studies of the ubiquitin-proteasome system, which has profound implications in cancer biology. In addition to degrading specific cyclin proteins during progression of the cell cycle, and generating peptide antigens that are bound and presented to the immune system by the major histocompatibility complex, the ubiquitin-proteasome system was also found to generate intracellular peptides with profound regulatory activity and importance $(135,136)$. Accordingly, a comprehensive screen for such intracellular peptides in synchronized HeLa cells identified a small peptide derived from the proteolysis of cyclin D2, specifically the $\alpha 5$ helix of the cyclin box, which induces cell death via apoptosis and/or necrosis in all cell lines tested (i.e., broad-spectrum efficacy), including human cervical cancer, breast cancer, melanoma and thyroid tumor-derived lines (136). Moreover, when this cyclin D2 $\alpha 5$ helix-derived peptide is fused to a cell-penetrating peptide, the resulting construct, infused in vivo in a rat brain tumor model, reduced the volume of rat C6 glioblastomas by $\sim 50 \%$ (136). Using a fluorescently labeled peptide monitored by real-time confocal microscopy in MDA-MB-231 breast cancer cells, the $\alpha 5$ helix-derived peptide entered the cells within min, localized to the nucleus as well as the cytoplasm, and induced cell death in breast cancer cells, specifically in G1/S-arrested cells and in cells that were actively progressing through $\mathrm{S}$ phase (137).

Reasoning that the protein/protein interface and conformational changes required in the molecular mechanism of cyclin-dependent CDK activation would be potential targets for the design of specific inhibitors of cell cycle progression, a small peptide inhibitor $(\mathrm{C} 4)$ derived from the $\alpha 5$ helix (aa 285-306) of cyclin A was found to be capable of binding to cyclin A/CDK2 complexes, thereby inhibiting the kinase activity of kinase complexes harboring CDK 2 in a competitive manner (138). Intricate structural studies indicate that this $\mathrm{C} 4$ ( $\alpha 5$ helix) peptide binds to the active site of CDK2 to interfere with the interaction of target phosphoacceptor substrates, independently of ATP binding in the catalytic site, thus overcoming one of the major drawbacks of inhibitors that target the ATP-binding site of protein kinases (which tend to result in poor selectivity) and introducing a novel class of designer 
peptide inhibitors of cyclin-dependent kinase activation, with the potential to treat a wide range of tumor types (138). The cytotoxic efficacy of this C4 ( $\alpha 5$ helix) peptide was validated in cellulo by demonstrating that proliferation of all the human tumor cell lines tested (breast cancer, liver cancer and T-cell leukemia) is blocked in a dose-dependent manner when the C4 ( $\alpha 5$ helix) peptide is coupled to a cell-penetrating carrier peptide (138).

As both the crystal structure of cyclin A and the mechanism of cyclin A/CDK2 interaction have been extensively characterized (134), and the major contact points with the catalytic CDK subunit have been determined to be the $\alpha 3, \alpha 4$ and $\alpha 5$ helices of the cognate cyclin subunit, the demonstration that the 'designer' peptide inhibitor $\mathrm{C} 4(\alpha 5$ helix) does not compete with cyclin $\mathrm{A}$ in terms of cyclin A/CDK2 complex formation, nor does it simply interact with monomeric CDK2; rather, the binding of cyclin A to CDK2 promotes a conformational change in CDK2 that exposes the substrate docking site on the $\mathrm{CDK}$, thereby facilitating the binding of the $\mathrm{C} 4$ ( $\alpha 5$ helix) across the catalytic cleft of CDK2 and blocking the phosphorylation of target substrates (138). Based on the profound mechanistic insights provided by this detailed structure-activity analysis, as well as the broad-spectrum anticancer efficacy demonstrated by the cyclin D1-derived $\alpha 5$ helix peptide, recently identified by functional proteomics $(136,137)$, we may now present a clearer and more comprehensive picture of the molecular mechanisms by which the dnG1 construct, developed by direct experimentation (77) and embodied by Rexin-G in clinical medicine (98), is able to produce such broad-spectrum anticancer efficacy when administered repeatedly as a single therapeutic agent (Tables I and II).

Clearly, dnG1, which is structurally truncated, and yet retains the $\alpha 3, \alpha 4$ and $\alpha 5$ helices of the predicted substrate (c-Myc) docking site (Fig. 9), presents a rational, stable and competitive intracellular inhibitor of cyclin G1/CKD5 activity (and possibly cyclin G1/CDK2 activity), which blocks the phosphorylation/activation of c-Myc, thwarts proliferative competence and leads to cell death via apoptosis and necrosis in cancer cells derived from all three germ layers, save for artificially-immortalized 'vector producer' cell lines (e.g., 293T cells) that have been purposefully transformed by the strategic integration of the SV40 large T antigen, a dominant-acting oncoprotein, which coincidently targets pRb, p53 and PP2A for subversion (139) and often leads to malignant transformation. Retaining the structural interaction domains that bind $\mathrm{Mdm} 2$ and PP2A, the C-terminus of cyclin G1 not only exhibits the PP2A-B' $\gamma$ association domain, it apparently 'displays' this domain at least an order of magnitude more efficiently as a protein than the ELAS1 peptide drug, which was designed to mimic, thus compete with, this interaction (133). Of note, this ELAS1 peptide (thus dnG1) was found to sensitize U2OS osteosarcoma cells to radiation therapy (RT), as well as camptothecan/irinotecan chemotherapy (140), thereby providing a new avenue for dnG1 (Rexin-G) to further improve the efficacy of chemoradiotherapy (CRT).

While the p53 tumor suppressor normally guards DNA fidelity and serves as the executioner (by inducing apoptosis) of aberrant cells, this locus of control is frequently lost in the process of cell transformation, tumorigenesis, invasion, EMT and/or metastasis, as the balance of power, i.e., the dominance of the commanding axis, shifts from p53 tumor suppression to the oncogenic cyclin G1/Mdm2 phenotype. From a therapeutic aspect, dnG1 functions mechanistically, hence clinically, to counteract the root proliferative competence of cancer cells, that being the pro-survival, anti-apoptotic, tumor-promoting actions of cyclin G1/CDK activity associated with the phosphorylation/activation of the c-Myc oncoprotein. In retaining the structural elements and interfaces of the commanding cyclin G1/Mdm2/p53 axis that interact with Mdm2 and PP2A, the dnG1 protein provides an additional means of sensitizing cancer cells to RT, cytotoxic chemotherapies and CRT. In the revealing crucible of clinical medicine, wherein investigational new drugs, such as Rexin-G, are initially tested under rather extreme conditions (e.g., late-stage, metastatic and/or chemotherapy-resistant cancers) wherein standard therapies have failed, the repeated clinical demonstrations of tumor eradication (in the presence or absence of p53) in multiform cancer types, including eradication of primary tumors, metastatic lesions, and even lymphatic metastasis $(98,99)$, resulting in long-term dose-dependent survival benefits (101), provides a compelling molecular exemplar for the future of cancer gene therapy.

\section{Conclusions along with a note concerning the future of clinical oncology}

The commanding cyclin G1/Mdm2/p53 axis is presented herein with collegial appreciation for the multidisciplinary nature of the task: The decades of basic, translational and clinical cancer research that has brought this 'accessible' locus of checkpoint control to light. The model is purposefully simple yet powerful in its applications, intended to provide a logical framework for new information, including the development of pertinent companion diagnostics, and to serve as a guide for clinical oncologists to better understand the executive regulatory components that determine the efficacy and outcomes of cancer therapies through the increasingly complex molecular mechanisms of cell cycle checkpoint control. This review is presented in appreciation of the numerous cancer patients whose informed consent has served to teach and tell, and whose long-term, cancer-free survival stands as a meaningful milestone in clinical oncology.

The broad-spectrum, single-agent efficacy of Mx-dnG1 (Rexin-G) demonstrated in end-stage cancers, where standard therapies had failed, is an excellent step forward; and one can only imagine what improved clinical outcomes may arise when the physiological surveillance properties of the tumor-targeted Mx-dnG1 vector is eventually permitted to be administered worldwide at an earlier, less intractable stage of metastatic cancer (Figs. 5 and 8). Furthermore, these first pioneering demonstrations of clinical safety, efficacy and long-term survival of Mx-dnG1 (Rexin-G)-treated cancer patients serve as a challenge to those who may otherwise distort or obscure what has been historically accomplished, and to serve as a guidepost for the next generation of clinical oncologists who will assuredly be more knowledgeable and skilled in applied molecular medicine. Finally, this review article is presented well in advance of the time when genetic medicine will no 
longer be viewed as a competitive (or disruptive) biotechnology, but will rather be considered a rational and beneficial addition to the combinatorial practice of the postmodern medical oncologist.

\section{Acknowledgements}

The authors gratefully acknowledge Heather C. Gordon for graphic illustrations and previous funding from the National Science Foundation, National Institutes of Health, NATO Scientific Exchange Program, American Heart Association, Whittier Family Foundation, and the FDA Orphan Drug Program in support of this pioneering biomedical research.

\section{Funding}

Funded in part by the Sarcoma Oncology Center, 2811 Wilshire Blvd., Suite 414, Santa Monica CA 90403, USA, and in part by DELTA Next-Gen, LLC, 2700 Neilson Way, Suite 1423, Santa Monica CA 90405, USA.

\section{Availability of data and materials}

The materials included in this manuscript, including all relevant raw data, will be made freely available to any researchers who wish to use this for non-commercial purposes, while preserving any necessary confidentiality and anonymity.

\section{Authors' contributions}

EG reviewed the published literature, wrote the manuscript, analyzed the critical stages in Rexin-G drug development, reviewed and edited the final manuscript. JR reviewed the published literature, wrote sections of the manuscript and the reference section, and edited the final manuscript. SL reviewed the published literature, wrote and edited the reference section, and edited the final manuscript. SC reviewed the published literature, analyzed the clinical trials using Rexin-G, reviewed and edited the final manuscript. FH reviewed the published literature, analyzed the molecular mechanisms of action of cyclin G1 in the cell cycle control pathway, wrote the manuscript, reviewed and edited the final manuscript. All authors approve the submission of this manuscript for publication.

\section{Ethics approval and consent to participate}

Not applicable.

\section{Patient consent for publication}

Not applicable.

\section{Competing interests}

Drs Gordon and Hall are co-inventors of Rexin-G targeted gene delivery system, which was developed at the University of Southern California Keck School of Medicine, and are co-founders of DELTA Next-Gen, LLC. Dr Chawla, Mr. Ravicz and Mr. Liu have no competing interests to disclose.

\section{References}

1. Goel G, Makkar HP, Francis G and Becker K: Phorbol esters: Structure, biological activity, and toxicity in animals. Int J Toxicol 26: 279-288, 2007.

2. Weinstein IB: The origins of human cancer: Molecular mechanisms of carcinogenesis and their implications for cancer prevention and treatment-twenty-seventh G.H.A. Clowes memorial award lecture. Cancer Res 48: 4135-4143, 1988.

3. Kikkawa U, Takai Y, Tanaka Y, Miyake R and Nishizuka Y: Protein kinase $\mathrm{C}$ as a possible receptor protein of tumor-promoting phorbol esters. J Biol Chem 258: 11442-11445, 1983.

4. Cooke M, Magimaidas A, Casado-Medrano V and Kazanietz MG: Protein kinase $\mathrm{C}$ in cancer: The top five unanswered questions. Mol Carcinog 56: 1531-1542, 2017.

5. Reid BJ, Culotti JG, Nash RS and Pringle JR: Forty-five years of cell-cycle genetics. Mol Biol Cell 26: 4307-4312, 2015.

6. Yasutis KM and Kozminski KG: Cell cycle checkpoint regulators reach a zillion. Cell Cycle 12: 1501-1509, 2013.

7. Jackson PK: The hunt for cyclin. Cell 134: 199-202, 2008.

8. Reed SI: G1 specific cyclins: In search for an S-phase promoting factor. Trends Genet 7: 95-99, 1991.

9. Pines J and Hunter T: Cyclin-dependent kinases: A new cell cycle motif? Trends Cell Biol 1: 117-121, 1991.

10. Kishimoto T: Entry into mitosis: A solution to the decades-long enigma of MPF. Chromosoma 124: 417-428, 2015.

11. Nasmyth K: Viewpoint: Putting the cell cycle in order. Science 274: 1643-1645, 1996.

12. Strausfeld UP, Howell M, Descombes P, Chevalier S, Rempel RE, Adamczewski J, Maller JL, Hunt T and Blow JJ: Both cyclin A and cyclin $\mathrm{E}$ have S-phase promoting (SPF) activity in Xenopus egg extracts. J Cell Sci 109: 1555-1563, 1996.

13. Vulliet PR, Hall FL, Mitchell JP and Hardie DG: Identification of a novel proline-directed serine/threonine protein kinase in rat pheochromocytoma. J Biol Chem 264: 16292-16298, 1989.

14. Hall FL, Mitchell JP and Vulliet PR: Phosphorylation of synapsin I at a novel site by proline-directed protein kinase. J Biol Chem 265: 6944-6948, 1990.

15. Hall FL and Vulliet PR: Proline-directed protein phosphorylation and cell cycle regulation. Curr Opin Cell Biol 3: 176-184, 1991.

16. Suzuki M: SPXX, a frequent sequence motif in gene regulatory proteins. J Mol Biol 207: 61-84, 1989.

17. Hall FL, Braun RK, Mihara K, Fung YT, Berndt N, Carbonaro-Hall DA and Vulliet PR: Characterization of the cytoplasmic proline-directed protein kinase in proliferative cells and tissues as a heterodimer comprised of p34cdc2 and p58cyclin A. J Biol Chem 266: 17430-17440, 1991.

18. Elledge SJ, Richman R, Hall FL, Williams RT, Lodgson N and Harper JW: CDK2 encodes a 33-kDa cyclin A-associated protein kinase and is expressed before CDC2 in the cell cycle. Proc Natl Acad Sci USA 89: 2907-2911, 1992.

19. Peeper DS, Parker LL, Ewen ME, Toebes M, Hall FL, Xu M, Zantema A, van der Eb AJ and Piwnica-Worms H: A- and B-type cyclins differentially modulate substrate specificity of cyclincdk complexes. EMBO J 12: 1947-1954, 1995.

20. Giacinti $\mathrm{C}$ and Giordano A: RB and cell cycle progression. Oncogene 25: 5220-5227, 2006.

21. Bertoli C and Skotheim JM and de Bruin RA: Control of cell cycle transcription during G1 and S phases. Nat Rev Mol Cell Biol 14: 518-528, 2013.

22. Foster DA, Yellen P, Xu L and Saqcena M: Regulation of G1 cell cycle progression: Distinguishing the restriction point from a nutrient-sensing cell growth checkpoint(s). Genes Cancer 1: 1124-1131, 2010.

23. Csikász-Nagy A, Kapuy O, Tóth A, Pál C, Jensen LJ, Uhlmann F, Tyson JJ and Novák B: Cell cycle regulation by feed-forward loops coupling transcription and phosphorylation. Mol Syst Biol 5: 236, 2009.

24. Weinberg RA: The biology of cancer, 2nd edition, Chapter 9: p53 and apoptosis: Master guardian and executioner. Garland Sci, New York, 2014.

25. Vermeulen K, Van Bockstaele DR and Berneman ZN: The cell cycle: A review of regulation, deregulation and therapeutic targets in cancer. Cell Prolif 36: 131-149, 2003.

26. Deshpande A, Sicinski P and Hinds PW: Cyclins and cdks in development and cancer: A perspective. Oncogene 24, 2909-2915, 2005.

27. Malumbres M: Cyclin-dependent kinases. Genome Biol 15: 122, 2014. 
28. Sherr CJ and McCormick F: The RB and $\mathrm{p} 53$ pathways in cancer. Cancer Cell 2: 103-112, 2002.

29. Giordano A, McCall C, Whyte P and Franza BR Jr: Human cyclin A and the retinoblastoma protein interact with similar but distinguishable sequences in the adenovirus E1A gene product. Oncogene 6: 481-485, 1991.

30. Wang J, Chenivesse X, Henglein B and Bréchot C: Hepatitis B virus integration in a cyclin A gene in a hepatocellular carcinoma. Nature 343: 555-557, 1990.

31. Wang J, Zindy F, Chenivesse X, Lamas E, Henglein B and Bréchot C: Modification of cyclin A expression by hepatitis B virus DNA integration in a hepatocellular carcinoma. Oncogene 7: 1653-1656, 1992

32. Bréchot C: Oncogenic activation of cyclin A. Curr Opin Genet Dev 3: 11-18, 1993.

33. Bodey B, Williams RT, Carbonaro-Hall DA, Horvath A, Tolo VT, Luck JV Jr, Taylor CR and Hall FL: Immunocytochemical detection of cyclin A and cyclin D in formalin-fixed, paraffin-embedded tissues: Novel, pertinent markers of cell proliferation. Mod Pathol 7: 846-852, 1994.

34. Motokura T and Arnold A: Cyclin D and oncogenesis. Curr Opin Genet Dev 3: 5-10, 1993.

35. Hunter T and Pines J: Cyclins and Cancer II: Cyclin D and CDK inhibitors come of age. Cell 79: 573-582, 1994,

36. Santamaria D, Barrière C, Cerqueira A, Hunt S, Tardy C, Newton K, Cáceres JF, Dubus P, Malumbres M and Barbacid M: Cdk1 is sufficient to drive the mammalian cell cycle. Nature 448: 811-815, 2007.

37. Blagosklonny MV and Pardee AB: The restriction point of the cell cycle. Cell Cycle 1: 103-110, 2002.

38. Hwang HC and Clurman BE: Cyclin $\mathrm{E}$ in normal and neoplastic cell cycles. Oncogene 24: 2776-2786, 2005.

39. Narasimha AM, Kaulich M, Shapiro GS, Choi YJ, Sicinski P and Dowdy SF: Cyclin D activates the Rb tumor suppressor by mono-phosphorylation. Elife 3, 2014. doi: 10.7554/eLife.02872.

40. El-Deiry WS: p21(WAF1) mediates cell cycle inhibition, relevant to cancer suppression and therapy. Cancer Res 76: 5189-5191, 2016.

41. Roussel MF: The INK4 family of cell cycle inhibitors in cancer. Oncogene 18: 5311-5317, 1999.

42. Serrano M, Lee H, Chin L, Cordon-Cardo C, Beach D and DePinho RA: Role of the INK4a locus in tumor suppression and cell mortality. Cell 85: 27-37, 1996.

43. Shapiro GI and Harper JW: Anticancer drug targets: Cell cycle and checkpoint control. J Clin Invest 104: 1645-1653, 1999.

44. Casimiro MC, Velasco-Velázquez $\mathrm{M}$, Aguirre-Alvarado $\mathrm{C}$ and Pestell RG: Overview of cyclins D1 function in cancer and the CDK inhibitor landscape: Past and present. Expert Opin Investig Drugs 23: 295-304, 2014.

45. Abbas T and Dutta A: p21 in cancer: Intricate networks and multiple activities. Nat Rev Cancer 9: 400-414, 2009.

46. Peyressatre M, Prével C, Pellerano M and Morris MC: Targeting cyclin-dependent kinases in human cancers: From small molecules to Peptide inhibitors. Cancers (Basel) 7: 179-237, 2015.

47. Asghar U, Witkiewicz AK, Turner NC and Knudsen ES: The history and future of targeting cyclin-dependent kinases in cancer therapy. Nat Rev Drug Discov 14: 130-146, 2015.

48. Sherr CJ, Beach D and Shapiro GI: Targeting CDK4 and CDK6: From discovery to therapy. Cancer Discov 6: 353-367, 2016.

49. Horne MC, Goolsby GL, Donaldson KL, Tran D, Neubauer M and Wahl AF: Cyclin G1 and Cyclin G2 comprise a new family of cyclins with contrasting tissue-specific and cell cycle-regulated expression. J Biol Chem 271: 6050-6061, 1996.

50. Wu L, Liu L, Yee A, Carbonarohall D, Tolo V and Hall F: Molecular-cloning of the human CYCG1 gene encoding a G-type cyclin-overexpression in human osteosarcoma cells. Oncol Rep 1: 705-711, 1994.

51. Okamoto $\mathrm{K}$ and Beach D: Cyclin $\mathrm{G}$ is a transcriptional target of the p53 tumor suppressor protein. EMBO J 13: 4816-4822, 1994

52. Efeyan A and Serrano M: p53: Guardian of the genome and policeman of the oncogenes. Cell Cycle 6: 1006-1010, 2007.

53. Smith ML, Kontny HU, Bortnick R and Fornace AJ Jr: The p53-regulated cyclin $\mathrm{G}$ gene promotes cell growth: p53 downstream effectors cyclin $\mathrm{G}$ and Gadd45 exert different effects on cisplatin chemosensitivity. Exp Cell Res 230: 61-68, 1997.

54. Skotzko M, Wu L, Anderson WF, Gordon EM and Hall FL: Retroviral vector-mediated gene transfer of antisense Cyclin G1 (CYCG1) inhibits proliferation of human osteogenic sarcoma cells. Cancer Res 55: 5493-5498, 1995.
55. Chen DS, Zhu NL, Hung G, Skotzko MJ, Hinton DR, Tolo V, Hall FL, Anderson WF and Gordon EM: Retroviral vector-mediated transfer of an antisense cyclin G1 construct inhibits osteosarcoma tumor growth in nude mice. Hum Gene Ther 8: 1667-1674, 1997.

56. Hung G, Skotzko MJ, Chang M, Zhu NL, Parekh D, Hall FL, Gordon EM and Anderson WF: Intratumoral injection of an antisense cyclin G1 retroviral vector inhibits growth of undifferentiated carcinoma xenografts in nude mice. Pediatr Hematol Oncol 4: 317-325, 1997.

57. Piette J, Neel H and Maréchal V: Mdm2: Keeping p53 under control. Oncogene 15: 1001-1010, 1997.

58. Momand J, Jung D, Wilczynski S and Niland J: The MDM2 gene amplification database. Nucleic Acids Res 26: 3453-3459, 1998.

59. Haupt S, Vijayakumaran R, Miranda PJ, Burgess A, Lim E and Haupt Y: The role of MDM2 and MDM4 in breast cancer development and prevention. J Mol Cell Biol 9: 53-61, 2017.

60. Momand J, Zambetti GP, Olson DC, George D and Levine AJ: The mdm-2 oncogene product forms a complex with the p53 protein and inhibits p53-mediated transactivation. Cell 69: $1237-1245,1992$.

61. Iwakuma T and Lozano G: DM2, an introduction. Mol Cancer Res 1: 993-1000, 2003.

62. Shi D and Gu W: Dual roles of MDM2 in the regulation of p53: Ubiquitination dependent and ubiquitination independent mechanisms of MDM2 repression of p53 activity. Genes Cancer 3: 240-248, 2012.

63. Shangary S and Wang S: Targeting the MDM2-p53 interaction for cancer therapy. Clin Cancer Res 14: 5318-5324, 2008.

64. Tisato V, Voltan R, Gonelli A, Secchiero P and Zauli G: MDM2/X inhibitors under clinical evaluation: Perspectives for the management of hematological malignancies and pediatric cancer. J Hematol Oncol 10: 133, 2017.

65. Estrada-Ortiza N, Neochoritisa CG and Dömlinga A: How to design a successful p53-MDM2/X interaction inhibitor: A thorough overview based on crystal structures. Chem Med Chem 11: 757-772, 2016.

66. Meek DW and Knippschild U: Posttranslational modification of MDM2. Mol Cancer Res 1: 1017-1026, 2003.

67. Okamoto K, Kamibayashi C, Serrano M, Prives C, Mumby MC and Beach D: p53-dependent association between cyclin G and the B' subunit of protein phosphatase 2A. Mol Cell Biol 16: 6593-6602, 1996.

68. Okamoto K, Li H, Jensen MR, Zhang T, Taya Y, Thorgeirsson SS and Prives C: Cyclin G recruits PP2A to dephosphorylate Mdm2. Mol Cell 9: 761-771, 2002.

69. Westermarck J and Hahn WC: Multiple pathways regulated by the tumor suppressor PP2A in transformation. Trends Mol Med 14: 152-160, 2008.

70. Kimura SH and Nojima H: Cyclin G1 associates with MDM2 and regulates accumulation and degradation of $\mathrm{p} 53$ protein. Genes Cells 7: 869-880. 2002.

71. Giono LE and Manfredi JJ: The p53 tumor suppressor participates in multiple cell cycle checkpoints. J Cell Physiol 209: 13-20, 2006.

72. Chen X: Cyclin G: A regulator of the p53-Mdm2 network. Dev Cell 2: 518-519, 2002.

73. Jensen MR, Factor VM, Fantozzi A, Helin K, Huh CG and Thorgeirsson SS: Reduced hepatic tumor incidence in cyclin G1-deficient mice. Hepatology 37: 862-870, 2003.

74. Zhu NL, Wu L, Liu PX, Gordon EM, Anderson WF, Starnes VA and Hall FL: Down-regulation of cyclin G1 expression by retrovirus-mediated antisense gene transfer inhibits vascular smooth muscle cell proliferation and neointima formation. Circulation 96: 628-635, 1997.

75. Kampmeier J, Behrens A, Wang Y, Yee A, Anderson WF, Hall FL, Gordon EM and McDonnell PJ: Inhibition of rabbit keratocyte and human fetal lens epithelial cell proliferation by retroviral-mediated transfer of antisense cyclin G1 and antisense MAT1 constructs. Hum Gene Ther 11: 1-8, 2000.

76. Jensen MR, Factor VM and Thorgeirsson SS: Regulation of Cyclin G1 during murine hepatic regeneration following Dipin-induced DNA damage. Hepatology 28: 537-546, 1998.

77. Xu F, Prescott MF, Liu PX, Chen ZH, Liau G, Gordon EM and Hall FL: Long term inhibition of neointima formation in balloon-injured rat arteries by intraluminal instillation of a matrix-targeted retroviral vector bearing an improved cytocidal Cyclin G1 construct. Int J Mol Med 8: 19-30, 2001.

78. Waehler R, Russell SJ and Curiel DT: Engineering targeted viral vectors for gene therapy. Nature Rev Genet 8: 573-587, 2007. 
79. Hall FL, Gordon EM, Wu L, Zhu NL, Skotzko MJ, Starnes VA and Anderson WF: Targeting retroviral vectors to vascular lesions by genetic engineering of the MoMLV gp70 envelope protein. Hum Gene Ther 8: 2183-2192, 1997.

80. Weimin Wu B, Cannon PM, Gordon EM, Hall FL and Anderson WF: Characterization of the proline-rich region of murine leukemia virus envelope protein. J Virol 72: 5383-5391, 1998.

81. Hall FL, Liu L, Zhu NL, Stapfer M, Anderson WF, Beart RW and Gordon EM: Molecular engineering of matrix-targeted retroviral vectors incorporating a surveillance function inherent in von Willebrand factor. Hum Gene Ther 11: 983-993, 2000.

82.Zhu NL, Gordon EM, Liu L, Terramani T, Anderson WF and Hall FL: Collagen-targeted retroviral vectors displaying domain D2 of von Willebrand factor (vWF-D2) enhance gene transfer to human tissue explants. Int J Pediatr Hematol Oncol 7: 325-335, 2001.

83. Gordon EM, Zhu NL, Forney Prescott M, Chen ZH, Anderson WF and Hall FL: Lesion-targeted injectable vectors for vascular restenosis. Hum Gene Ther 12: 1277-1287, 2001.

84. Behrens A, Gordon EM, Li L, Liu PX, Chen Z, Peng H, La Bree L, Anderson WF, Hall FL and McDonnell PJ: Retroviral gene therapy vectors for prevention of excimer laser-induced corneal haze. Invest Ophthalmol Vis Sci 43: 968-977, 2002.

85. Song JC, McDonnell PJ, Gordon EM, Hall FL and Anderson WF: Phase I/II evaluation of safety and efficacy and a matrix-targeted retroviral vector bearing a dominant negative cyclin $\mathrm{G} 1$ construct (Mx-dnG1) as adjunctive intervention for superficial corneal opacity/corneal scarring. Hum Gene Ther 14: 306-309, 2003.

86. Gordon EM, Liu PX, Chen ZH, Liu L, Whitley MD, Gee C, Groshen S, Hinton DR, Beart RW and Hall FL: Inhibition of metastatic tumor growth in nude mice by portal vein infusions of matrix-targeted retroviral vectors bearing a cytocidal cyclin G1 construct. Cancer Res 60: 3343-3347, 2000.

87. Gordon EM, Liu PX, Chen ZH, Liu L, Whitley M, Liu L, Wei D, Groshen S, Hinton DR, Anderson WF, Beart RW Jr and Hall FL: Systemic administration of a matrix-targeted retroviral vector is efficacious for cancer gene therapy in mice. Hum Gene Ther 12 193-204, 2001.

88.Lenz HJ, Anderson WF, Hall FL and Gordon EM: Tumor site specific phase I evaluation of safety and efficacy of hepatic arterial infusion of a matrix-targeted retroviral vector bearing a dominant negative Cyclin G1 construct as treatment for colorectal carcinoma metastatic to liver. Hum Gene Ther 13 1515-1537, 2002.

89. Le Tourneau C, Lee JJ and Siu LL: Dose escalation methods in phase I cancer clinical trials. JNatl Cancer Inst 101: 708-720,2009.

90. Gordon EM, Cornelio GH, Lorenzo CC III, Levy JP, Reed RA, Liu L and Hall FL: First clinical experience using a 'pathotropic' injectable retroviral vector (Rexin-G) as intervention for stage IV pancreatic cancer. Int J Oncol 24: 177-185, 2004.

91. Gordon EM, Lopez FF, Cornelio GH, Lorenzo CC III, Levy JP, Reed RA, Liu L, Bruckner HW and Hall FL: Pathotropic nanoparticles for cancer gene therapy Rexin-G IV: Three-year clinical experience. Int J Oncol 29: 1053-1064, 2006.

92. Galanis E, Carlso SK, Foster NR, Lowe V, Quevedo F, McWilliams RR, Grothey A, Jatoi A, Alberts SR and Rubin J: Phase I trial of a pathotropic retroviral vector expressing a cytocidal cyclin G1 construct (Rexin-G) in patients with advanced pancreatic cancer. Mol Ther 16: 979-984, 2008.

93. Chawla SP, Chua VS, Mohan V, Alzwahereh K, Kalra A, Quon D, Gordon EM and Hall FL: Phase I/II study of targeted gene delivery in vivo-intravenous infusions of Rexin-G demonstrate significant biologic activity by FDG PET-CT without toxicity in patients with progressive chemo-resistant sarcoma, breast cancer and pancreatic cancer. J Clin Oncol 26 (15-Suppl) S14509-S14509, 2008

94. Chawla SP, Chua VS, Fernandez L, Quon D, Saralou A, Blackwelder WC, Hall FL and Gordon EM: Evaluation of the safety and efficacy of 'pathotropic' nanoparticles bearing a dominant-negative Cyclin G1 construct (Rexin-G) as monotherapy for chemo-resistant osteosarcoma and other sarcomas-phase I/II and phase II studies. J Clin Oncol 27: 10513-10513, 2009

95. Chawla SP, Chua VS, Fernandez L, Quon D, Saralou A, Blackwelder WC, Hall FL and Gordon EM: Phase I/II and phase II studies of targeted gene delivery in vivo: intravenous Rexin-G for chemotherapy-resistant sarcoma and osteosarcoma. Mol Ther 17: 1651-1657, 2009.
96.Chawla SP, Chawla NS, Quon D, Chua-Alcala V Blackwelder WC, Hall FL and Gordon EM: An advanced phase $1 / 2$ study using an XC-targeted gene therapy vector for chemotherapy resistant sarcoma. Sarcoma Res Int 3: 1024-1031, 2016

97. Chawla SP, Chua VS, Fernandez L, Quon D, Blackwelder WC, Gordon EM and Hall FL: Advanced phase I/II studies of targeted gene delivery in vivo: Intravenous Rexin- $G$ for gemcitabine-resistant metastatic pancreatic cancer. Mol Ther 18: 435-441, 2010.

98. Gordon EM and Hall FL: Rexin-G, a targeted genetic medicine for cancer. Expert Opin Biol Ther 10: 819-832, 2010.

99. Gordon EM, Chan MT, Geraldino N, Lopez FF, Cornelio GH, Lorenzo CC III, Levy JP, Reed RA, Liu L and Hall FL: Le morte du tumour: Histological features of tumor destruction in chemo-resistant cancers following intravenous infusions of pathotropic nanoparticles bearing therapeutic genes. Int J Oncol 30: 1297-1307, 2007.

100. Gordon EM and Hall FL: A primer on pathotropic medicine. In 'one hundred years of the FDA and the future of global health. Brooklands New Media Ltd, Shopshire UK: 84, 2007.

101. Kim S, Federman N, Gordon EM, Hall FL and Chawla SP: Rexin- $\mathrm{G}^{\circledR}$, a tumor-targeted retrovector for malignant peripheral nerve sheath tumor: A case report. Mol Clin Oncol 6: 861-865, 2017.

102. Feng Z, Zhang $\mathrm{C}$, $\mathrm{Wu} \mathrm{R}$ and $\mathrm{Hu} \mathrm{W}$ : Tumor suppressor $\mathrm{p} 53$ meets microRNAs. J Mol Cell Biol 3: 44-50, 2011.

103. Huang S and He X: The role of microRNAs in liver cancer progression. Br J Cancer 104: 235-240, 2011.

104. Gramantieri L, Ferracin M, Fornari F, Veronese A, Sabbioni S, Liu CG, Calin GA, Giovannini C, Ferrazzi E, Grazi LG, et al: Cyclin G1 is a target of miR-122a, a microRNA frequently down-regulated in human hepatocellular carcinoma. Cancer Res 67: 6092-6099, 2007.

105. Coulouarn C, Factor VM, Andersen JB, Durkin ME and Thorgeirsson SS: Loss of miR-122 expression in liver cancer correlates with suppression of the hepatic phenotype and gain of metastatic properties. Oncogene 28: 3526-3536, 2009.

106. Fornari F, Gramantieri L, Giovannini C, Veronese A, Ferracin M, Sabbioni S, Calin GA, Grazi GL, Croce CM, Tavolari S, et al: MiR-122/cyclin G1 interaction modulates p53 activity and affects doxorubicin sensitivity of human hepatocarcinoma cells. Cancer Res 69: 5761-5767, 2009.

107. Wu X, Wu S, Tong L, Luan T, Lin L, Lu S, Zhao W, Ma Q, Liu $\mathrm{H}$ and Zhong Z: miR-122 affects the viability and apoptosis of hepatocellular carcinoma cells. Scand J Gastroenternol 44: 1332-1339, 2009.

108. Ma L, Liu J, Shen J, Liu L, Wu J, Li W, Luo J, Chen Q and Qian C: Expression of miR-122 mediated by adenoviral vector induces apoptosis and cell cycle arrest of cancer cells. Cancer Biol Ther 9: 554-561, 2010.

109. Hsu SH, Wang B, Kota J, Yu J, Costinean S, Kutay H, Yu L, Bai S, La Perle K, Chivukula RR, et al: Essential metabolic, anti-inflammatory, and anti-tumorigenic functions of miR-122 in liver. J Clin Invest 122: 2871-2883, 2012.

110. Bandopadhyay M, Sarkar N, Datta S, Das D, Pal A, Panigrahil R, Banerjee A, Panda CK, Das C, Chakrabarti S and Chakravarty R: Hepatitis B virus X protein mediated suppression of miRNA-122 expression enhances hepatoblastoma cell proliferation through cyclin G1-p53 axis. Infect Agent Cancer 11: 40, 2016.

111. Reimer CL, Borras AM, Kurdistani SK, Garreau JR, Chung M, Aaronson SA and Lee SW: Altered regulation of Cyclin G in human breast cancer and its specific localization at replication foci in response to DNA damage in p53+/+ cells. J Biol Chem 274: 11022-11029, 1999.

112. Perez R, Wu N, Klipfel AA and Beart RW Jr: A better cell cycle target for gene therapy of colorectal cancer: Cyclin G. J Gastrointest Surg 7: 884-889, 2003.

113. Wen W, Ding J, Sun W, Fu J, Chen Y, Wu K, Ning B, Han T, Huang L, Chen C, et al: Cyclin G1-mediated epithelial-mesenchymal transition via phosphoinositide 3-kinase/Akt signaling facilitates liver cancer progression. Hepatology 55: 1787-1798, 2012.

114. Weinstein B and Joe A: Oncogene addiction. Cancer Res 68: 3077-3080, 2008

115. Li H, Okamoto K, Peart MJ and Prives C: Lysine-independent turnover of Cyclin G1 can be stabilized by B'alpha subunits of protein phosphatase 2A. Mol Cell Biol 29: 919-928, 2009. 
116. Piscopo DM and Hinds PW: A role for the cyclin box in the ubiquitin-mediated degradation of cyclin G1. Cancer Res 68: 5581-5590, 2008

117. Seo HR, Kim J, Bae S, Soh JW and Lee YS: Cdk5-mediated phosphorylation of c-Myc on Ser-62 is essential in transcriptional activation of cyclin B1 by Cyclin G1. J Biol Chem 283: 15601-15610, 2008.

118. Menssen A and Hermeking H: Characterization of the c-MYC-regulated transcriptome by SAGE: Identification and analysis of c-MYC target genes. Proc Natl Acad Sci USA 99: 6274-6279, 2002.

119. Morita N, Kiryu S and Kiyama H: p53-independent Cyclin $\mathrm{G}$ expression in a group of mature neurons and its enhanced expression during nerve regeneration. J Neurosci 16: 5961-5966, 1996.

120. Sultana R and Butterfield DA: Regional expression of key cell cycle proteins in brain from subjects with amnestic mild cognitive impairment. Neurochem Res 32: 655-662, 2007.

121. Yang Y, Mufson EJ and Herrup K: Neuronal cell death is preceded by cell cycle events at all stages of Alzheimer's disease. J Neurosci 23: 2557-2563, 2003.

122.Lee MS, Kwon YT, Li M, Peng J, Friedlander RM and Tsai LH: Neurotoxicity induces cleavage of p35 to p25 by calpain. Nature 405: 360-364, 2000.

123. Ko J, Humbert S, Bronson RT, Takahashi S, Kulkarni AB Li E and Tsai L: p35 and p39 are essential for cyclin-dependent kinase 5 function during neurodevelopment. J Neurosci 21: 6758-6771, 2001.

124. Cheung ZH, Gong K and Ip NY: Cyclin-dependent kinase 5 supports neuronal survival through phosphorylation of Bcl-2. J Neurosci 28: 4872-4877, 2008.

125. Cruz JC, Tseng HC, Goldman JA, Shih H and Tsai LH: Aberrant Cdk5 activation by p25 triggers pathological events leading to neurodegeneration and neurofibrillary tangles. Neuron 40 : 471-483, 2003.

126. Tansey WP: Mammalian MYC proteins and cancer. New J Sci 2014: Article ID 757534, 2014.

127. Dang CV, Reddy EP, Shokat KM and Soucek L: Drugging the 'undruggable' cancer targets. Nat Rev Cancer 17: 502-508, 2017.

128.Zhang W, Xu J, Ji D, Li Z, He W, Yang F, Lan H, Wang Y, Wu Z, Liu X, et al: Cyclin G1 amplification enhances aurora kinase inhibitor-induced polyploid resistance and inhibition of Bcl-2 pathway reverses the resistance. Cell Physiol Biochem 43: 94-107, 2017.

129. Russell P, Hennessy BT, Li J, Carey MS, Bast RC, Freeman T and Venkitaraman AR: Cyclin G1 regulates the outcome of taxane-induced mitotic checkpoint arrest. Oncogene 31: 2450-2460, 2012
130. Shang Y, Feng B, Zhou L, Ren G, Zhang Z, Fan X, Sun Y, Luo G, Liang J, Wu K, et al: The miR27b-CCNG1-P53-miR-508-5p axis regulates multidrug resistance of gastric cancer. Oncotarget 7: $538-549,2015$

131.Zhang H, Hao Y, Yang J, Zhou Y, Li J, Yin S, Sun C, Ma M, Huang $\mathrm{Y}$ and $\mathrm{Xi} J \mathrm{~J}$ : Genome-wide functional screening of miR-23b as a pleiotropic modulator suppressing cancer metastasis. Nat Commun 2: 554, 2011.

132. Yan J, Jiang JY, Meng XN, Xiu YL and Zong ZH: MiR-23b targets cyclin G1 and suppresses ovarian cancer tumorigenesis and progression. J Exp Clin Cancer Res 35: 31, 2016.

133. Uchihashi T, Ota K, Yabuno Y, Ohno S, Fukushima K, Naito Y, Kogo M, Yabuta N and Nojima H: ELAS1 induces apoptotic death in adenocarcinoma DU145 and squamous-cell carcinoma SAS cancer cells, but not in normal KD cells. Oncotarget 8: 85868-85882, 2017.

134. Brown NR, Noble ME, Endicott JA, Garman EF, Wakatsuki S, Mitchell E, Rasmussen B, Hunt T and Johnson LN: The crystal structure of Cyclin A. Structure 3: 1235-1247, 1995.

135. Ferro ES, Hyslop S and Camargo AC: Intracellullar peptides as putative natural regulators of protein interactions. J Neurochem 91: 769-777, 2004.

136. de Araujo CB, Russo LC, Castro LM, Forti FL, do Monte ER, Rioli V, Gozzo FC, Colquhoun A and Ferro ES: A Novel intracellular peptide derived from $\mathrm{g} 1 / \mathrm{s}$ cyclin $\mathrm{d} 2$ induces cell death. J Biol Chem 289: 16711-16726, 2014.

137. Russo LC, Araujo CB, Iwai LK, Ferro ES and Forti FL: A cyclin D2-derived peptide acts on specific cell cycle phases by activating ERK1/2 to cause the death of breast cancer cells. J Proteomics 151: 24-32, 2017.

138. Gondeau C, Gerbal-Chaloin S, Bello P, Aldrian-Herrada G, Morris MC and Divita G: Design of a novel class of peptide inhibitors of cyclin-dependent kinase/cyclin activation. J Biol Chem 280: 13793-13800, 2005.

139. Ahuja D, Sáenz-Robles MT and Pipas JM: SV40 large T antigen targets multiple cellular pathways to elicit cellular transformation. Oncogene 24: 7729-7745, 2005.

140. Ohno S, Naito Y, Mukai S, Yabuta $N$ and Nojima $H$ : ELAS1-mediated inhibition of the cyclin G1-B' $\gamma$ interaction promotes cancer cell apoptosis via stabilization and activation of p53. Oncogene 34: 5983-5996, 2015.

This work is licensed under a Creative Commons Attribution-NonCommercial-NoDerivatives 4.0 International (CC BY-NC-ND 4.0) License. 